\title{
One-pot synthesis of hydrophilic flower-shaped iron oxide nanoclusters (IONCs) based ferrofluids for magnetic fluid hyperthermia applications
}

\author{
Ganeshlenin Kandasamy a,b , Shaheen Khan ${ }^{\text {c }}$, Jyotsnendu Giri ${ }^{\mathrm{d}}$, Suryasarathi Bose ${ }^{\mathrm{e}}$, \\ Naga Suresh Veerapu ${ }^{\mathrm{c}}$, Dipak Maity ${ }^{\mathrm{a}, \mathrm{f}, *}$ \\ a Department of Mechanical Engineering, Shiv Nadar University, Dadri, Uttar Pradesh, India \\ ${ }^{\mathrm{b}}$ Department of Biomedical Engineering, St. Peter's Institute of Higher Education and Research, Chennai, Tamil Nadu, India \\ c Department of Life Sciences, Shiv Nadar University, Dadri, Uttar Pradesh, India \\ d Department of Biomedical Engineering, Indian Institute of Technology - Hyderabad (IITH), Hyderabad, Telangana, India \\ e Department of Materials Engineering, Indian Institute of Science (IISc), Bangalore, Karnataka, India \\ f Department of Chemical Engineering, Institute of Chemical Technology (ICT Mumbai - IOC), Bhubaneswar, OR, India
}

\section{A R T I C L E I N F O}

\section{Article history:}

Received 6 August 2018

Received in revised form 19 November 2018

Accepted 21 November 2018

Available online 23 November 2018

\section{Keywords:}

Flower-shaped magnetic particles

Superparamagnetic iron oxides nanoclusters

Aqueous ferrofluids

Magnetic fluid hyperthermia

Thermotherapy

Biomedical applications

\begin{abstract}
A B S T R A C T
Herein, flower-shaped hydrophilic superparamagnetic iron oxide nanoclusters (IONCs) are synthesized via onepot thermolysis of iron acetylacetonate using triethanolamine (TEA) and diethylene glycol (DEG)/tetraethylene glycol (TTEG) mixtures at 9:1, 8:2 and 7:3 (v/v) ratios. The as-prepared 24-29 nm sized IONCs have displayed (i) saturation magnetization (Ms) values of $\sim 68-78 \mathrm{emu} / \mathrm{g}$, (ii) hydrodynamic diameters of $\sim 95-192 \mathrm{~nm}$ and (iii) zeta potential values of +46 to $+65 \mathrm{mV}$. Due to relatively high magnetization and water solubility, IONCs (prepared using 8:2 TEA:DEG, and 8:2 \& 7:3 TEA:TTEG ratios) based aqueous ferrofluids i.e. NCAFF-1, NCAFF-2, and NCAFF- 3 are investigated by calorimetric magnetic fluid hyperthermia (MFH) at $0.5-8 \mathrm{mg} / \mathrm{ml}$ concentrations by exposing them to the alternating magnetic fields (AMFs, $\mathrm{H}^{*} \mathrm{f} \sim 2.4-9.9 \mathrm{GA} \mathrm{m}^{-1} \mathrm{~s}^{-1}$ ). The NCAFF-3 has demonstrated excellent time dependent temperature rise $\left(42^{\circ} \mathrm{C}\right.$ within $\left.0.7-9.7 \mathrm{~min}\right)$ as compared to the NCAFF-1 and NCAFF-2. Moreover, the NCAFF- 3 at $0.5 \mathrm{mg} / \mathrm{ml}$ concentration has exhibited enhanced heating efficacies with specific absorption rate (SAR) and intrinsic loss power (ILP) values of $142.4-909.4 \mathrm{~W} / \mathrm{g}_{\mathrm{Fe}}$ and $4.2-14.7 \mathrm{nHm} / \mathrm{kg}$, respectively. Furthermore, the NCAFF- 3 has presented better cytocompatibility, and substantially reduced proliferation capacity of HepG2 cancer cells in in vitro MFH studies. Thus, the IONCs based ferrofluids (NCAFF3) are very promising candidates for MFH therapeutics applications.
\end{abstract}

(c) 2018 Elsevier B.V. All rights reserved.

\section{Introduction}

In the last few decades, newly developed nanomaterials have gained widespread attention, particularly for their feasible and effective application in cancer therapeutics to overcome the side-effects of the conventional treatment modalities. Recently, the treatment of cancers by using the magnetic nanoparticles (MNPs) has become very popular due to (i) critical inhibition of proliferation capacity of the cancer cells after their exposure to slightly elevated temperatures $\left(\sim 42-45{ }^{\circ} \mathrm{C}\right.$ as compared to the normal cells) [1-7], and (ii) magnetic targetingguided focused thermal treatment [8-10]. This cancer treatment modality is known as magnetic fluid hyperthermia (MFH) therapy/ thermotherapy, where the MNPs are utilized in the form of aqueous ferrofluids (AFFs) to induce intracellular localized heating on exposure

\footnotetext{
* Corresponding author at: Department of Mechanical Engineering, Shiv Nadar University, Dadri, Uttar Pradesh, India.

E-mail address: dipak.maity@snu.edu.in (D. Maity).
}

to an external alternating magnetic field (AMF) [11-14]. Apart from this MFH applications, the MNPs-based-AFFs are also intensively used for other major biomedical applications such as magnetofection [15-17], and magnetic resonance imaging (MRI) [18-23]. Generally, the AFFs are prepared by stabilizing single-core MNPs - especially superparamagnetic iron oxide nanoparticles (IONPs) -in an aqueous medium.

Now a days, synthesis of multi-core iron oxide nanoclusters (IONCs) has gained more importance due to their enhanced magnetization (saturation magnetization i.e. Ms) values as compared to the single-core IONPs, which is very essential for their effective MFH applications [24-27]. Initially, the IONCs are synthesized by coprecipitation of iron (II)/(III) salts in an aqueous medium using a base (e.g. tetramethylammonium hydroxide (TMAOH)) at lowtemperature $\left(80^{\circ} \mathrm{C}\right)$ conditions, but they are found to be less crystalline in nature and eventually possessed lower Ms values [27,28]. Then, the IONCs with improved crystallinity/Ms values are prepared via co-precipitation in a polyol medium using a base (e.g. sodium 
hydroxide $(\mathrm{NaOH}))$ at a slightly elevated temperature $\left(180-220^{\circ} \mathrm{C}\right)$ [25,26,29-32]. However, all these methods are majorly involved with (i) multi-step processes with longer reaction time periods ( 24-48 h), and (ii) complex/tedious surface-functionalization procedures by using citrate ions or polymers (acrylic-/styrenesulfonic-/ vinylsulfonic-acids) to stabilize the IONCs in an aqueous ferrofluids (AFFs) suspensions. To overcome these, Maity et al. have synthesized magnetite nanoclusters (MNCs or IONCs) based AFFs via one-step thermal decomposition (thermolysis) of iron precursors in a mixture of polyol at high temperatures [33], but these MNCs/IONCs have displayed higher particle sizes that might affect their relaxation mechanism in MFH studies. Nevertheless, in all of the above investigations, either high concentrations of the AFFs or higher amplitudes $(\mathrm{H}) /$ frequencies (f) of external magnetic fields (AMFs) are used to investigate the heating efficacies (i.e., specific absorption rate SAR values (in $\mathrm{W} / \mathrm{g}_{\mathrm{Fe}}$ ) or intrinsic loss power - ILP values (in $\mathrm{nHm}^{2} / \mathrm{kg}$ )) of the IONCs in MFH studies, which might lead to undesirable cytotoxicity/side effects or bring huge discomfort to the patients in clinical scenarios. So, there is a need for direct synthesis of high quality water-soluble IONCs based AFFs, and thorough inspection of their heating effects at lower concentrations on exposure of AMFs near to the biophysical safety limit (BPSL) - assessed by Hergt and Dutz for the MFH therapy [34].

In this work, we have initially focused on the one-pot synthesis of hydrophilic flower-shaped IONCs via thermolysis by using a specific liquid-solvent-surfactant (LSS) mixture of polyols (such as diethylene glycol (DEG) or tetraethylene glycol (TTEG), and triethanolamine), where influence of the polyols on physicochemical, magnetic and water dispersibility/solubility properties of the as-prepared IONCs are methodically explored. Then, we have systematically investigated the heating effects/efficacies (i.e., SAR/ILP) of the flower-shaped IONCs based AFFs (i.e. NCAFFs) in various concentrations and/or dispersion media on exposure to different AMFs near to the BPSL. Finally, in vitro cytocompatibility, cell uptake and MFH therapeutic efficacies of the selected NCAFFs (with high SAR/ILP values) are evaluated for their application in the liver cancer treatment.

\section{Experimental section}

\subsection{Chemicals}

Potassium thiocyanate (KSCN), potassium hexacyanoferrate (II) trihydrate $\left(\mathrm{K}_{4} \mathrm{Fe}(\mathrm{CN})_{6} \cdot 3 \mathrm{H}_{2} \mathrm{O}\right)$, and ferric acetylacetonate $\left(\mathrm{Fe}(\mathrm{acac})_{3}\right)$ are acquired from Sigma-Aldrich (France/Germany). Dulbecco's modified eagle medium (DMEM), fetal bovine serum (FBS), and phosphate buffer saline (PBS) are procured from Lonza/Gibco. Ethanol (EtOH, $\left.\mathrm{C}_{2} \mathrm{H}_{5} \mathrm{OH}\right)$, diethylene glycol (DEG, $\left.\left(\mathrm{HOCH}_{2} \mathrm{CH}_{2}\right)_{2} \mathrm{O}\right)$, triethanolamine (TEA, $\mathrm{C}_{6} \mathrm{H}_{15} \mathrm{NO}_{3}$ ), tetraethylene glycol (TTEG, $\mathrm{HO}$ $(\mathrm{CH} 2 \mathrm{CH} 2 \mathrm{O})_{3} \mathrm{CH}_{2} \mathrm{CH}_{2} \mathrm{OH}$ ), and ethyl acetate (EtOAc, $\mathrm{C}_{4} \mathrm{H}_{8} \mathrm{O}_{2}$ ) are bought from Fisher Scientific (India). All chemicals are acquired in reagent grade and used without any further purification.

\subsection{Synthesis and characterization of IONCS}

IONCs are synthesized by one-pot thermolysis as similar to our previously reported method with some modifications (as shown in Scheme 1A) [33]. Briefly, $2 \mathrm{mmol}$ ferric acetylacetonate $(\sim 0.706 \mathrm{~g})$ is dissolved in a $20 \mathrm{ml}$ LSS mixture of TEA \& DEG/TTEG at specific (v/v) ratios (i.e., 9:1, $8: 2$ and 7:3) within a 3-necked round bottom flask (RBF) - fixed with a water circulating condenser, where the ratios are selected based on our previously reported synthesis of IONCs using the TEA \& TEG [33] to prevent the formation single core IONPs. The RBF is kept in an electronically-controlled heating mantle, and the mixture solution is subsequently heated at $120{ }^{\circ} \mathrm{C}$ (dehydration temperature) for one hour $(1 \mathrm{~h})$ under nitrogen $\left(\mathrm{N}_{2}\right)$ gas flow with constant magnetic stirring. Next, the temperature of the mixture solution is increased to $\sim 245-250{ }^{\circ} \mathrm{C}$ (refluxing temperature) for thermolysis reaction and maintained for another $1 \mathrm{~h}$. Later, the following steps are performed in sequence: (i) the temperature of the resultant black-colored solution is brought down to room temperature (RT), (ii) the acquired IONCs are precipitated from the solution by using EtOAc, and (iii) the precipitated IONCs are washed three-times with a mixture of EtOH and EtOAc $(1: 2 \mathrm{v} / \mathrm{v})$ followed by centrifugation at $9500 \mathrm{rpm}$. Then, one half of the washed IONCs is mixed with EtOH and subsequently poured in a petri-dish, and further dried at $\sim 40{ }^{\circ} \mathrm{C}$ in an oven to obtain powdered samples (S1-S6 - refer Table 1). The other half of the washed IONCs is dispersed in Millipore water to obtain the AFFs and the iron (Fe) concentrations of the AFFs (with appropriate dilution) are determined by using KSCN [35]. Finally, the IONCs and AFFs samples are respectively stored in a desiccator (at RT) and a cold cabinet (at $4{ }^{\circ} \mathrm{C}$ ) for further characterizations. In addition, for comparison purposes, the MNCs (MNC-14) are also prepared at 4:1 ratio of TEA and TEG by exactly following our previously reported method [33].

The as-prepared IONCs samples (powders/AFFs) are characterized to investigate their physicochemical/magnetic/dispersibility properties using the techniques as follows: (i) morphology/size and SAEDP (selected area electron diffraction pattern) by transmission electron microscopy (TEM, JEM-2100, JEOL) operated at $200 \mathrm{kV}$; (ii) crystal structure by X-ray diffraction (XRD, Bruker D8 Advance) operated with $\mathrm{CuK} \alpha$ radiation (wavelength, $\lambda=1.54 \mathrm{~nm}$ ) and scanning angle of $20-80^{\circ}(2 \theta)$; (iii) amount of surface coating by thermogravimetric analyzer (TGA, Q500, TA Instruments) operated between RT and $800{ }^{\circ} \mathrm{C}$; (iv) magnetization by vibrating sample magnetometer (VSM, PAR 155) operated at RT; (v) type of surface coatings by Fourier transform infrared spectrometer (FTIR, Nicolet ${ }^{\mathrm{TM}}$ iS ${ }^{\mathrm{TM}}$ 5, Thermo Fisher) operated in $550-4000 \mathrm{~cm}^{-1}$ range at RT using the attenuated total reflection (ATR) process; and (vi) water solubility/dispersibility (in terms of zeta potential $(\zeta)$ /hydrodynamic diameters $\left(D_{h}\right)$ values) by dynamic light scattering (DLS, nanoPartica SZ-100-Z, Horiba) operated at standard $25^{\circ} \mathrm{C}$.

\subsection{Calorimetric magnetic fluid hyperthermia}

Based on the above mentioned characterizations, the selected IONCs are investigated further for their heat induction properties on exposure to the alternating magnetic fields (AMFs) generated by a magnetic fluid hyperthermia (MFH) instrument (nanoTherics) [36,37]. The MFH instrument mainly consists of $9 / 17$ turn coil that is used to produce the AMFs having definite amplitudes $(\mathrm{H})$ and frequencies (f), which can be varied in the range of $7.1 \mathrm{kA} / \mathrm{m}$ to $15.3 \mathrm{kA} / \mathrm{m}$, and $175.2 \mathrm{kHz}$ to $1001.1 \mathrm{kHz}$, respectively. The corresponding $\mathrm{H}^{*} \mathrm{f}$ values are calculated in the range of $2.4 \times 10^{9} \mathrm{Am}^{-1} \mathrm{~s}^{-1}$ to $9.9 \times 10^{9} \mathrm{Am}^{-1} \mathrm{~s}^{-1}$ (i.e. 2.4-9.9 GA m $\mathrm{m}^{-1} \mathrm{~s}^{-1}$ which are close to the assessed BPSL).

In a typical calorimetric MFH study (as shown in Scheme 1B), about 1 milliliter ( $\mathrm{ml}$ ) of the NCAFFs samples (i.e. selected IONCs dispersed in an aqueous suspension) is poured in a clean vial and a temperature probe is inserted into the suspension through its lid. The vial (along with the probe) is then affixed inside a Styrofoam container which is subsequently inserted into the space between the coils. The initial temperature of the NCAFFs samples is monitored for about $\sim 2$ min and then, the AMFs (with specific $\mathrm{H}^{*}$ f values) are produced to measure the time dependent temperature rise of the samples through the temperature probe (coupled to a data acquisition software, DAS). Finally, the time vs temperature graphs are plotted and the heating efficacies of the AFFs (i.e. SAR in $\mathrm{W} / \mathrm{g}_{\mathrm{Fe}}$ ) are calculated by using the following equation (Eq. (1)) based on the initial slopes of these graphs.

$\mathrm{SAR}=(\mathrm{dT} / \mathrm{dt}) *\left(\mathrm{C} / \mathrm{m}_{\mathrm{Fe}}\right)$

where, $\mathrm{dT} / \mathrm{dt}$ is initial slope of the time vs temperature graph, $\mathrm{C}$ is the specific heat capacity (in $\mathrm{J} \mathrm{kg}^{-1} \mathrm{~K}^{-1}$ ) of dispersion medium (for 


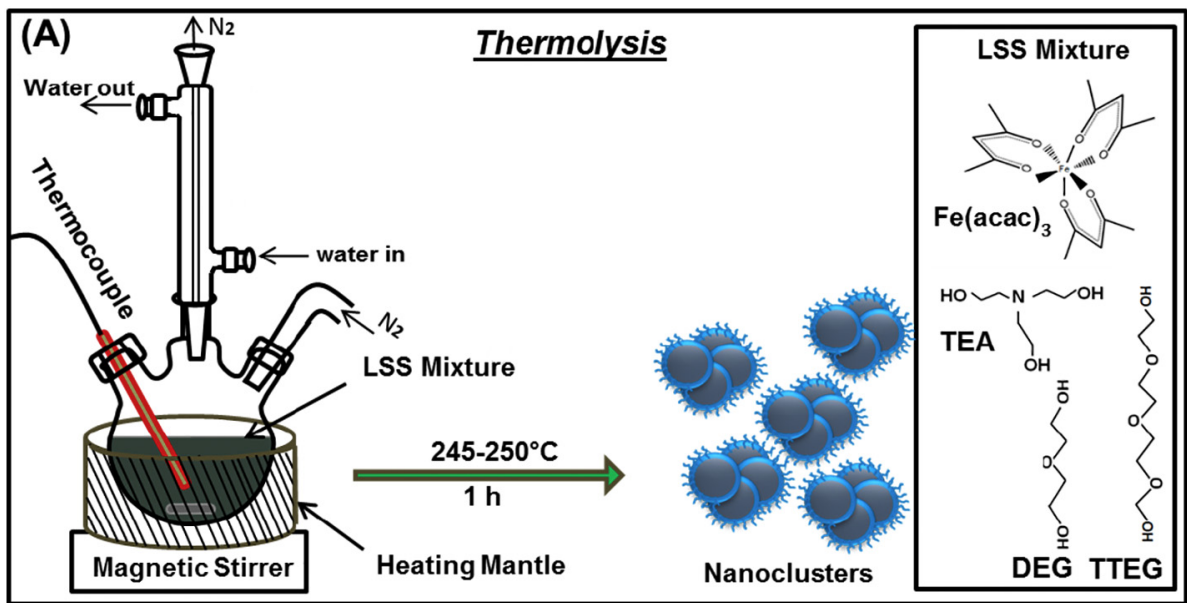

(B)

Magnetic Hvperthermia

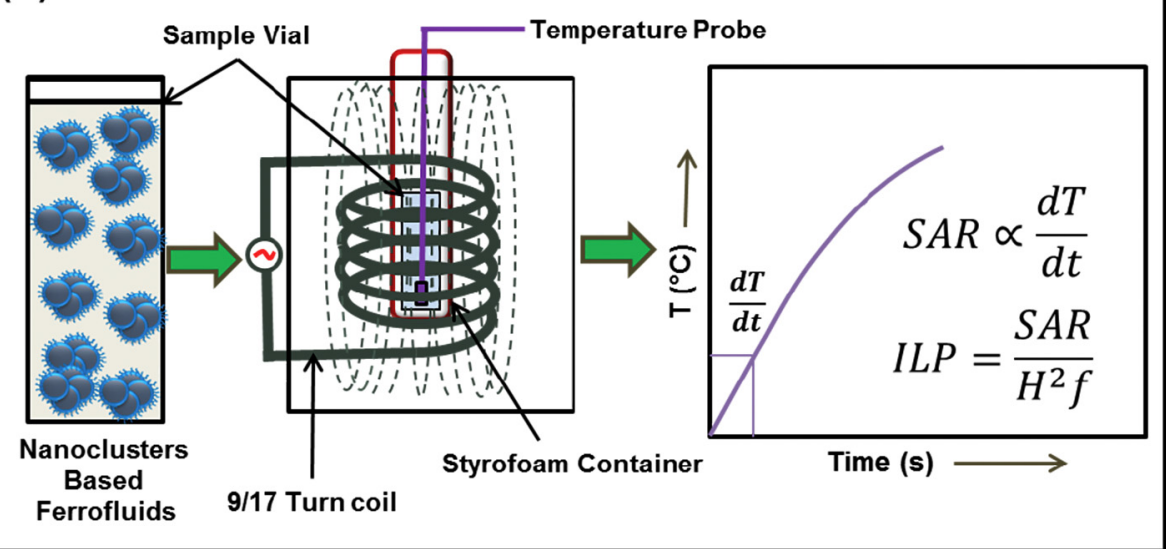

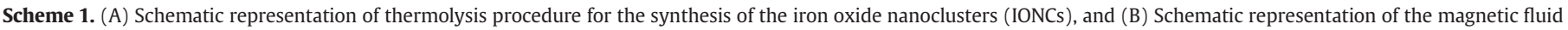
hyperthermia (MFH) set-up to study the time-dependent heating effects of the IONCs.

instance, water) and $\mathrm{m}$ is the mass (in grams, $\mathrm{g}$ ) of the IONCs (in terms of Fe - determined via KSCN method). The calorimetric studies are sequentially performed to investigate the influence of (i) concentration of the AFFs - varied in the range of $8-0.5 \mathrm{mg} / \mathrm{ml}$; (ii) applied AMFs $\left(\mathrm{H}^{*} \mathrm{f}\right)$ - varied in the range of 2.4-9.9 $\mathrm{GA} \mathrm{m}^{-1} \mathrm{~s}^{-1}$; and (iii) dispersion media - varied to disperse the IONCs in different biological media (DMEM/FBS/DMEM + 5\% $\mathrm{FBS} / \mathrm{PBS}$ ). Moreover, intrinsic loss power (ILP in $\mathrm{nHm}^{2} \mathrm{~kg}^{-1}$ ) is also

Table 1

Sample codes of the IONCs prepared by using the LSS mixture at different (TEA:polyol) ratios and their TEM - particle size (in nm), TGA - secondary weight loss ( in \%) and VSM Ms value (emu/g)

\begin{tabular}{|c|c|c|c|c|}
\hline $\begin{array}{l}\text { LSS mixture } \\
\text { (TEA:polyol } \\
\text { ratio) }\end{array}$ & $\begin{array}{l}\text { Sample code } \\
\text { (surface } \\
\text { coatings) }\end{array}$ & $\begin{array}{l}\text { TEM - } \\
\text { particle size } \\
(\sim \text { in } \mathrm{nm})\end{array}$ & $\begin{array}{l}\text { TGA - secondary } \\
\text { weight loss ( in } \\
\%)\end{array}$ & $\begin{array}{l}\text { VSM - Ms } \\
\text { (in } \\
\text { emu/g) }\end{array}$ \\
\hline \multicolumn{5}{|l|}{ TEA:DEG } \\
\hline $9: 1$ & S1 (TEA-DEG) & 25 & 12.1 & 71 \\
\hline $8: 2$ & S2 (TEA-DEG) & 27.6 & 11.7 & 73.2 \\
\hline $7: 3$ & S3 (TEA-DEG) & 24.5 & 11.6 & 67.6 \\
\hline \multicolumn{5}{|l|}{ TEA:TTEG } \\
\hline $9: 1$ & S4 (TEA-TTEG) & 27.4 & 9.3 & 74.1 \\
\hline $8: 2$ & S5 (TEA-TTEG) & 28.6 & 11.1 & 73.4 \\
\hline $7: 3$ & S6 (TEA-TTEG) & 29.4 & 7.7 & 77.8 \\
\hline \multicolumn{5}{|l|}{ TEA:TEG ${ }^{\mathrm{a}}$} \\
\hline $8: 2(4: 1)$ & MNC-14 (TEA-TEG) & 44 & 9 & 75 \\
\hline
\end{tabular}

a Our reported work. measured by normalizing SAR with respect to the applied AMF using the following equation (Eq. (2)).

$\mathrm{ILP}=\mathrm{SAR} /\left(\mathrm{H}^{2} \mathrm{f}\right)$

The ILP is a newly introduced parameter to make direct comparison (of the heating efficacies of SPIONs) among the diverse MFH experiments which are performed by different researchers by using various AMF (field strengths/frequency) conditions [38].

\subsection{Cytocompatibility and Cell Uptake of IONCS}

The cytocompatibility/biocompatibility of the selected IONCs is assessed in human liver cancer cell line (HepG2) as similar to our previous work with some modifications [37,39,40]. The HepG2 cancer cells are cultured in $25 \mathrm{~cm}^{2}$ tissue culture flask by using DMEM (supplemented with $10 \% \mathrm{FBS}$ ) under $37{ }^{\circ} \mathrm{C}$ incubation temperature and $5 \%$ $\mathrm{CO}_{2}$ environment. The confluent HepG2 cancer cells are trypsinized and centrifuged (at $1000 \mathrm{rpm}$ ) for 5 minutes (min) to get a cell pellet, which is resuspended in fresh DMEM. Then, the cells are seeded in a 24-well plate (from Nunc) and further incubated for 24 hours (h). After 70-80\% confluency, the cells are incubated with fresh-media having IONCs (at definite concentrations) in triplicates for $24 \mathrm{~h} / 48 \mathrm{~h}$. After the specific incubation periods, the HepG2 cancer cells are washed (using PBS - 3 times), and then incubated with fresh-media containing MTT for $4 \mathrm{~h}$. Then, the stopping solution is added to the wells for 


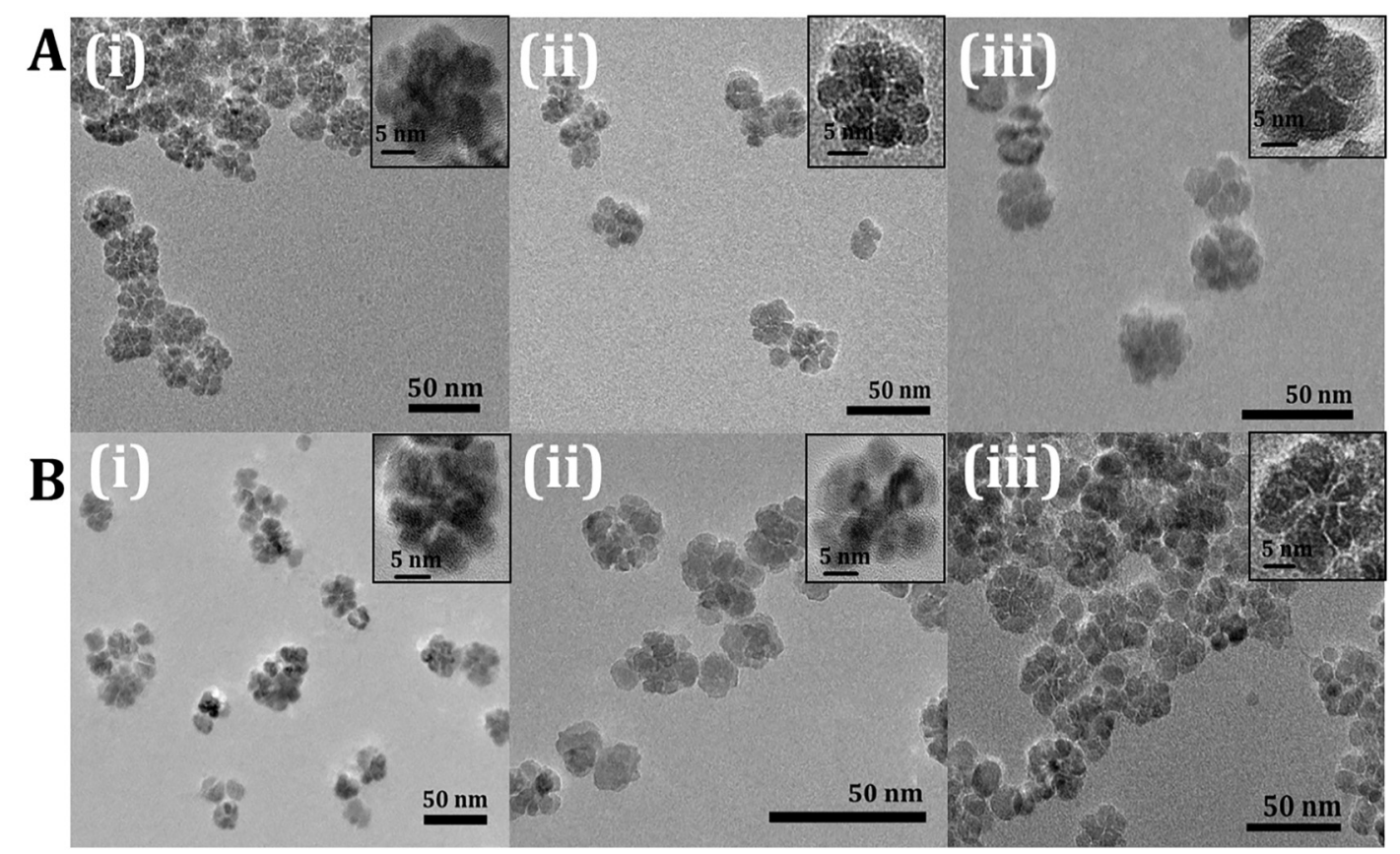

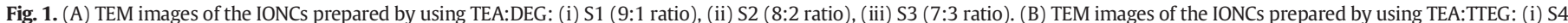
(9:1 ratio), (ii) S5 (8:2 ratio), (iii) S6 (7:3 ratio). Insets in (A) and (B) are the corresponding TEM images of a single nanocluster.

dissolving the as-formed formazan crystals, and the absorbance is measured using a microplate reader (Bio-Rad, US) at $595 \mathrm{~nm}$ [39]. The viability of the cells (to determine the cytocompatibility/biocompatibility of the IONCs) is calculated $(\mathrm{n}=3$ ) by using the following equation Eq. (3):

Cell viability(in\%)

$=(100 *($ Absorbance of control well $)) /($ Absorbance of sample well $)$

(3)
In cell uptake studies, the confluent HepG2 cancer cells (after $24 \mathrm{~h}$ incubation in a 24-well plate) are incubated with IONCs (dispersed in media at specific concentration) in triplicates for $24 / 48 \mathrm{~h}$. After incubation time, the following processes are performed in sequence: the cells are (i) 2-3 times washed with PBS; (ii) fixed with formaldehyde (4\%) and washed again with PBS; (iii) 20 min incubation with a mixturesolution containing potassium hexacyanoferrate $\left(\mathrm{K}_{4} \mathrm{Fe}(\mathrm{CN})_{6}\right)$ and $\mathrm{HCl}$, and then washed again with PBS; and (iv) finally imaged under optical microscope to confirm the cell uptake of IONCs via Prussian blue staining.

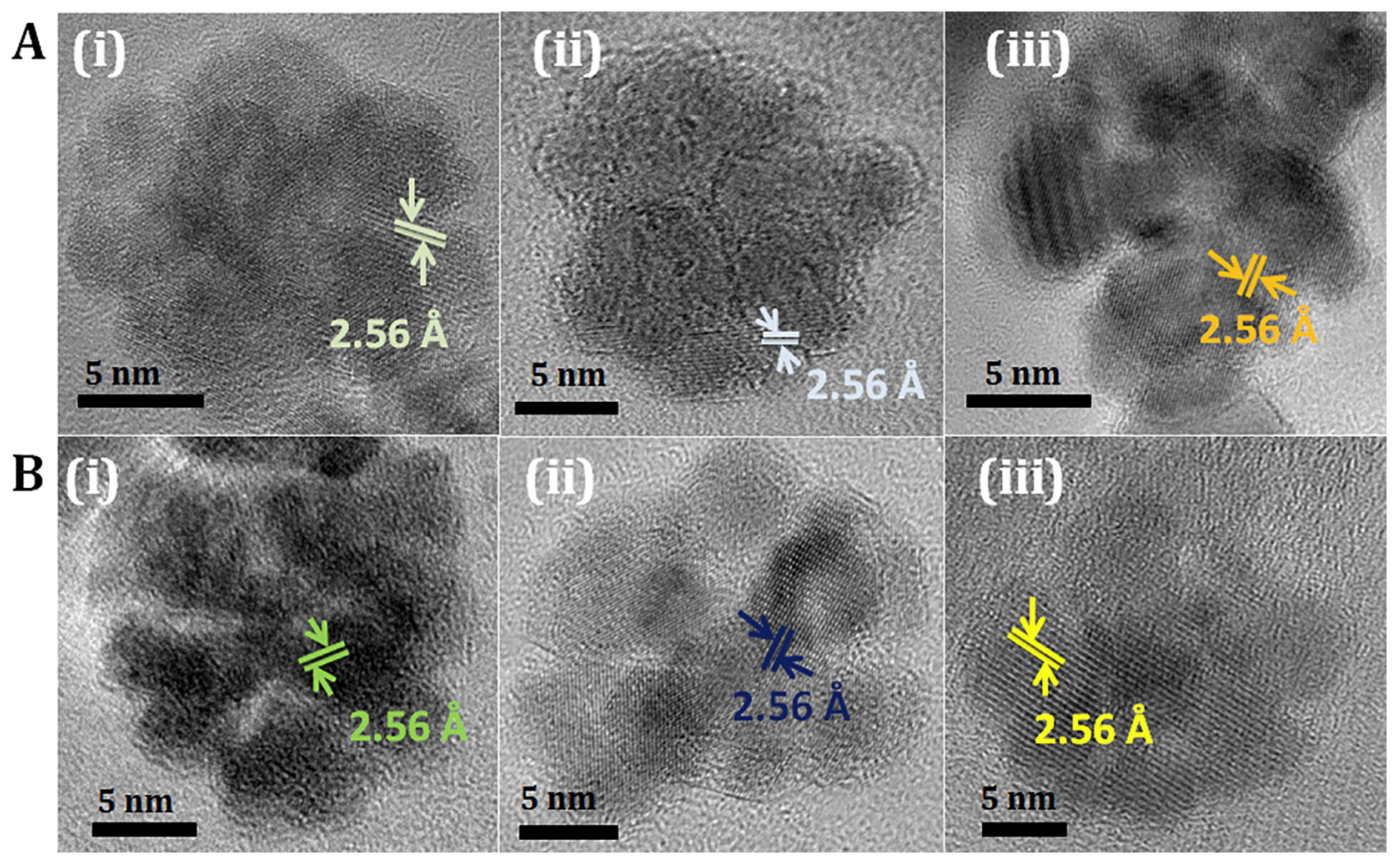

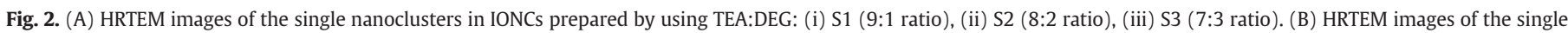
nanoclusters in IONCs prepared by using TEA:TTEG: (i) S4 (9:1 ratio), (ii) S5 (8:2 ratio), (iii) S6 (7:3 ratio). 


\subsection{In vitro magnetic fluid hyperthermia}

In a typical MFH therapeutic study, initially $\sim 7$ million HepG2 (liver) cancer cells are grown in a $75 \mathrm{~cm}^{2}$ culture-flask (at $37^{\circ} \mathrm{C}$, and $5 \% \mathrm{CO}_{2}$ ) by using DMEM $+10 \%$ FBS. After the cell growth, these HepG 2 cells are trypsinized and centrifuged (at $1000 \mathrm{rpm}$ ) to acquire them in a pellet form which is re-dispersed in $6 \mathrm{ml}$ media to form HepG2 cell stock. Then, $\sim 1$ million HepG 2 cells (from the stock) are placed in 6 separate sample vials (marked as V1, V2, V3, V4, V5 and V6).

The HepG2 cells in the V1 vial are used as control, and the cells in the V2 vial are subjected to only AMF (with $\mathrm{H}^{*}$ f value of $8.2 \mathrm{GA} \mathrm{m}^{-1} \mathrm{~s}^{-1}$ ) for
$1 \mathrm{~h}$. Moreover, the selected IONCs (based on the calorimetric study) are mixed with the HepG2 cells and incubated at $37^{\circ} \mathrm{C}$ for a time period of $15 \mathrm{~min}$ at (i) $0.5 \mathrm{mg} / \mathrm{ml}$ concentration in each of the V3 and V4 vials, and (ii) $1 \mathrm{mg} / \mathrm{ml}$ concentration in each of the V5 and V6 vials. Then, the HepG2 cells (along with IONCs) in the V4/V6 vial are exposed to the same AMF (as V2) to reach $\sim 42{ }^{\circ} \mathrm{C}$ (therapeutic heat/temperature), which is continued for next $1 \mathrm{~h}$ to provide the MFH treatment (by tuning the applied field). The HepG2 cells in V3/V5 are considered as corresponding counterparts (i.e., without field) for cells in V4/V6, to check the biocompatibility of the IONCs at their respective concentrations. After the MFH therapy, 35,000 HepG2 cells are taken from all
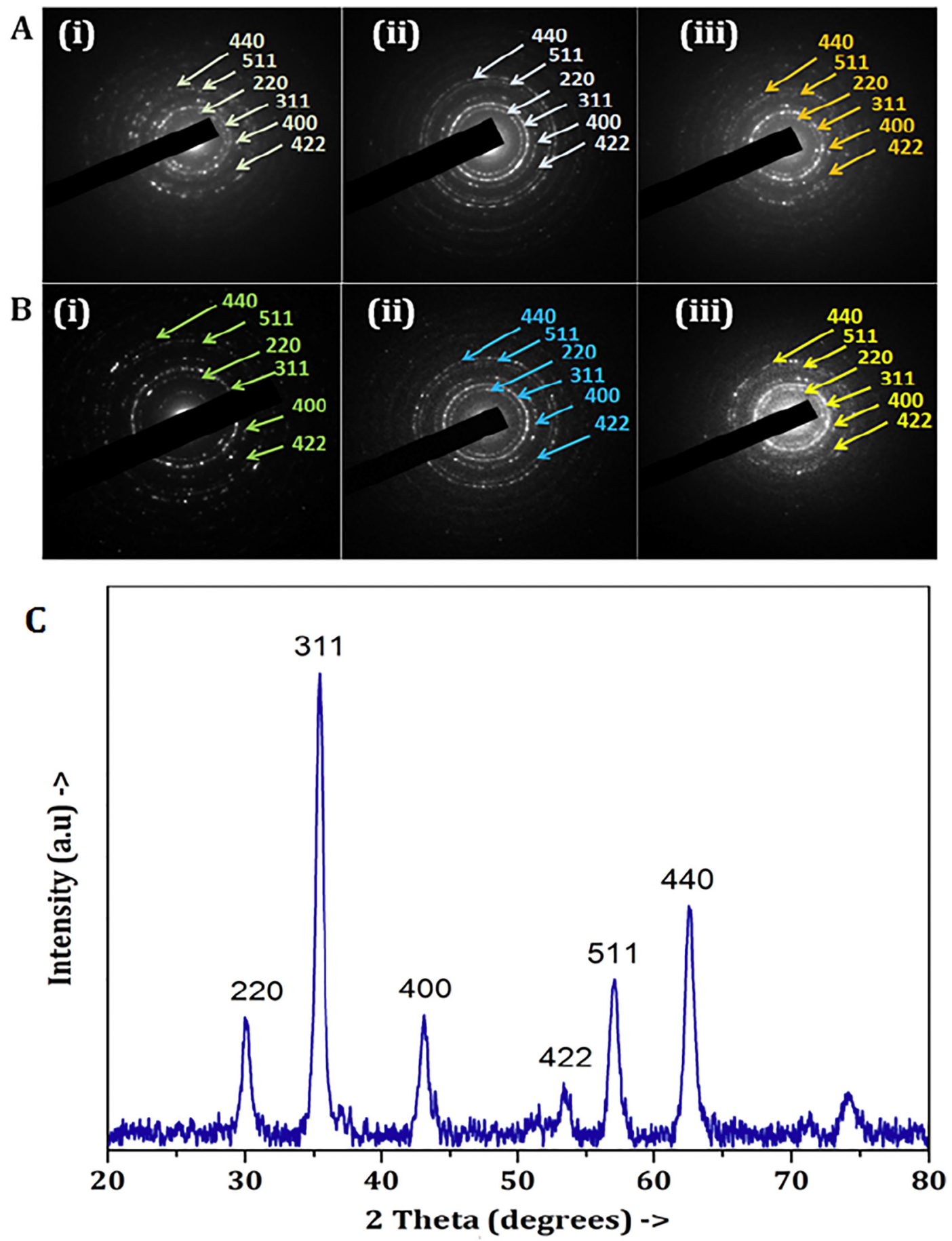

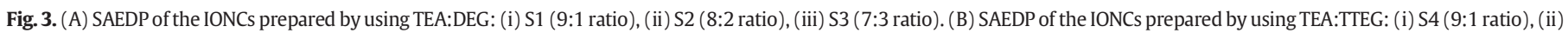
S5 (8:2 ratio), (iii) S6 (7:3 ratio). (C) XRD pattern of the sample S6 - IONCs prepared by using TEA:TTEG 7:3 ratio. 

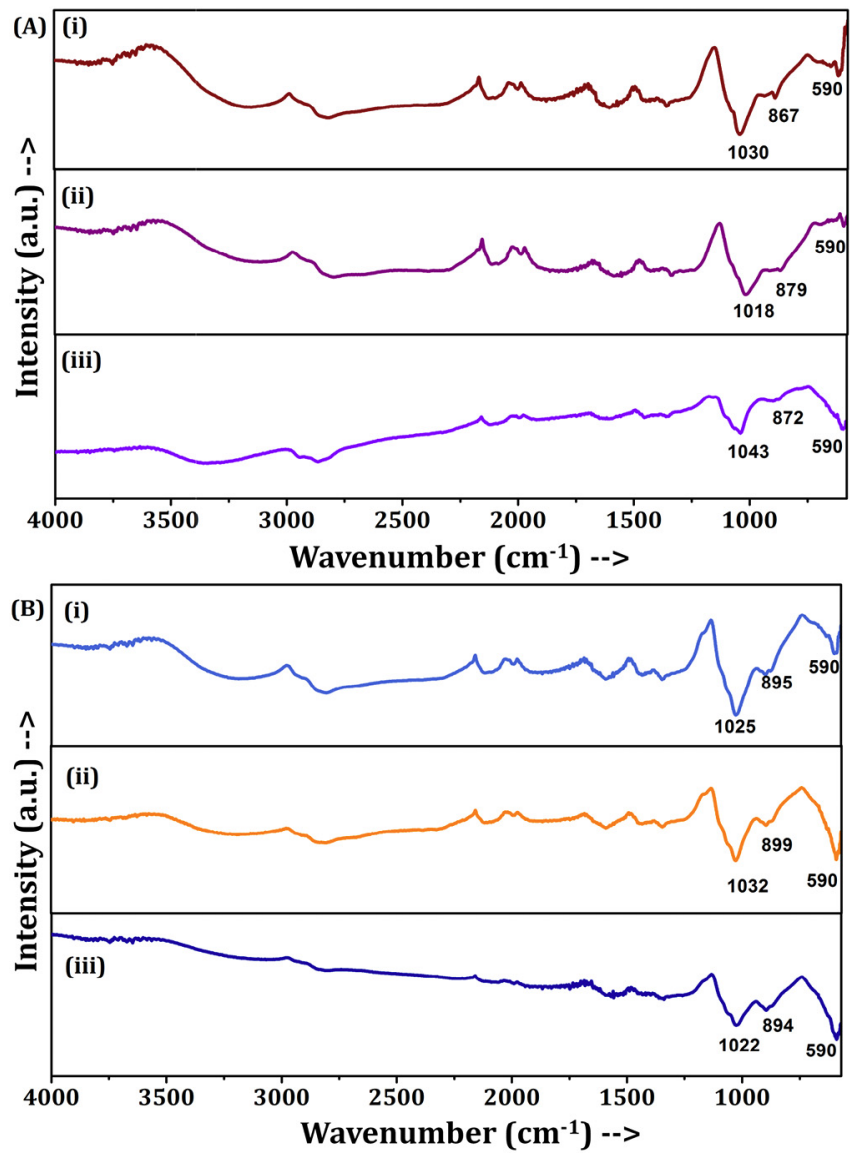

Fig. 4. (A) FTIR spectra of the IONCs prepared by using TEA:DEG: (i) S1 (9:1 ratio), (ii) S2 (8:2 ratio), (iii) S3 (7:3 ratio). (B) FTIR spectra of the IONCs prepared by using TEA:TTEG: (i) S4 (9:1 ratio), (ii) S5 (8:2 ratio), (iii) S6 (7:3 ratio).

sample vials (V1-V6) and mixed with appropriate quantity of DMEM $+10 \% \mathrm{FBS}$, which are further plated (in triplicates) and followed by $72 \mathrm{~h}$ incubation. Finally, viability of the HepG2 cells (from all wells) is assessed via MTT based procedure (based on Eq. (3)) to determine the cancer therapeutic efficacy of the IONCs.

\section{Results and discussions}

\subsection{Morphology/size - TEM}

Fig. 1A (i-iii) and B (i-iii) displays the TEM images of the S1-S3 and S4-S6 samples prepared by varying the ratios (9:1, 8:2 and 7:3) of TEA: DEG, and TEA:TTEG, respectively. The average particle sizes of the IONCs are measured (via Image J software) as $\sim 25 \mathrm{~nm}, \sim 27.6 \mathrm{~nm}$, and $\sim 24.5 \mathrm{~nm}$ for the S1, S2 and S3 samples, and $\sim 27.4 \mathrm{~nm}, \sim 28.6 \mathrm{~nm}$, and $\sim 29.4 \mathrm{~nm}$ for the S4, S5 and S6 samples, respectively (refer Table 1). Besides, the insets of Fig. 1A (i-iii) and B (i-iii) portray the TEM image of a single nanocluster which confirms the flower morphology of the IONCs for each of the corresponding samples. It can be noted that the particle sizes of the IONCs are varied with the type of polyol (DEG and TTEG) and the TEA:DEG/TEA:TTEG ratio. The average particle sizes of the IONCs prepared using TEA-TTEG mixtures are found to be slightly larger than the IONCs prepared using TEA-DEG mixtures, which could be mainly due to the influence of the longer chain length and/or higher boiling point of TTEG molecules as compared to the shorter chain length and/or lower boiling point of DEG molecules. Moreover, the average particle sizes of the as-prepared IONCs are found to be smaller than the previously reported MNC-14 nanoclusters (44 nm - refer Table 1) prepared at optimized 4:1 (i.e. 8:2) TEA:TEG ratio. Thus, TEM results indicating that the particle sizes of the IONCs could be altered with the variation of the polyol:TEA ratio and/or the type of polyol in the LSS mixtures used for their synthesis via thermolysis.

Furthermore, Fig. 2A (i-iii) and B (i-iii) displays the HRTEM images of the S1-S3 and S4-S6 samples prepared by varying the ratios (9:1, 8:2 and 7:3) of TEA:DEG, and TEA:TTEG respectively, in which the clearly visible lattice fringes confirm their highly crystalline nature. In addition, the lattice spacing of $2.56 \AA$ confirms the spacing between the (311) planes of crystalline magnetite $\left(\mathrm{Fe}_{3} \mathrm{O}_{4}\right)$ phase in the as-prepared IONCs. Moreover, Fig. 3A (i-iii) and B (i-iii) portrays the SAEDP of the S1-S3 and S4-S6 samples respectively, where the diffraction rings are resembled to the lattice planes - i.e., (440), (511), (220), (400), (422) and (311) of the crystalline magnetite $\left(\mathrm{Fe}_{3} \mathrm{O}_{4}\right)$ phase.

\subsection{Crystal structure - XRD}

Fig. 3C exhibits the XRD pattern of the IONCs prepared at 7:3 TEA: TTEG ratio (i.e., S6 sample), where the diffraction peaks are corresponded to the (440), (511), (220), (400), (422) and (311) lattice

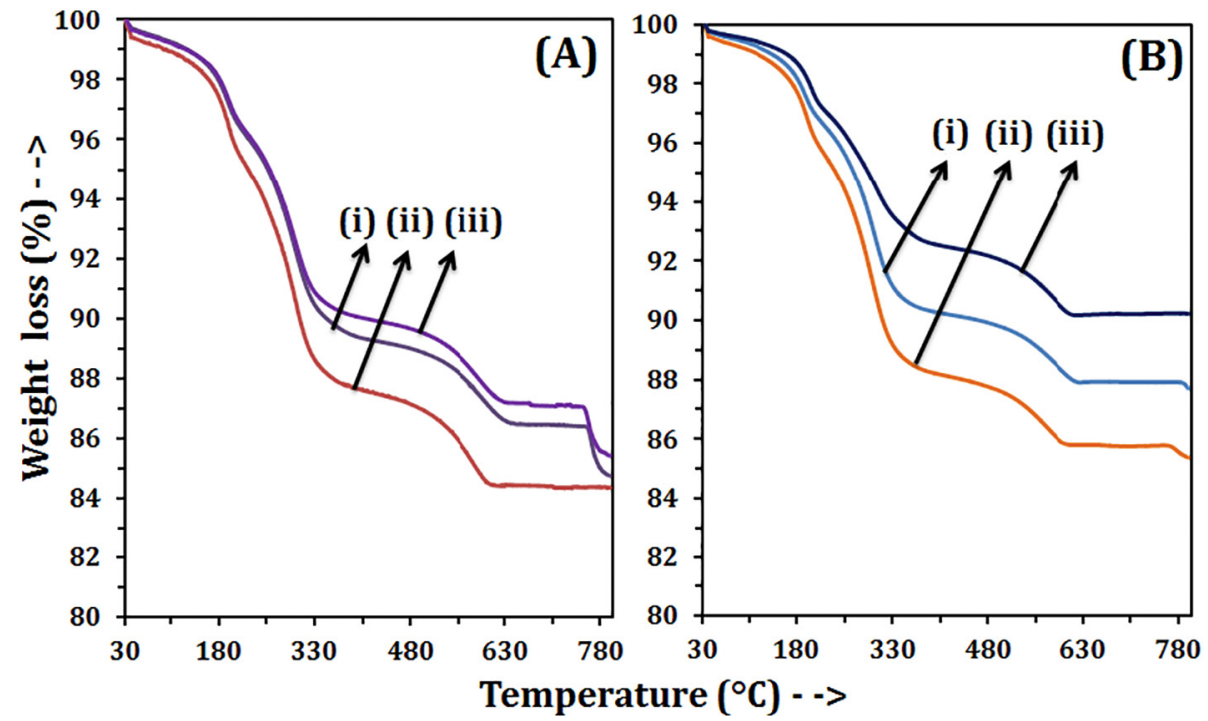

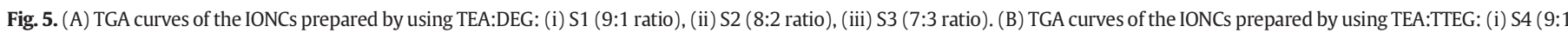
ratio), (ii) S5 (8:2 ratio), (iii) S6 (7:3 ratio). 


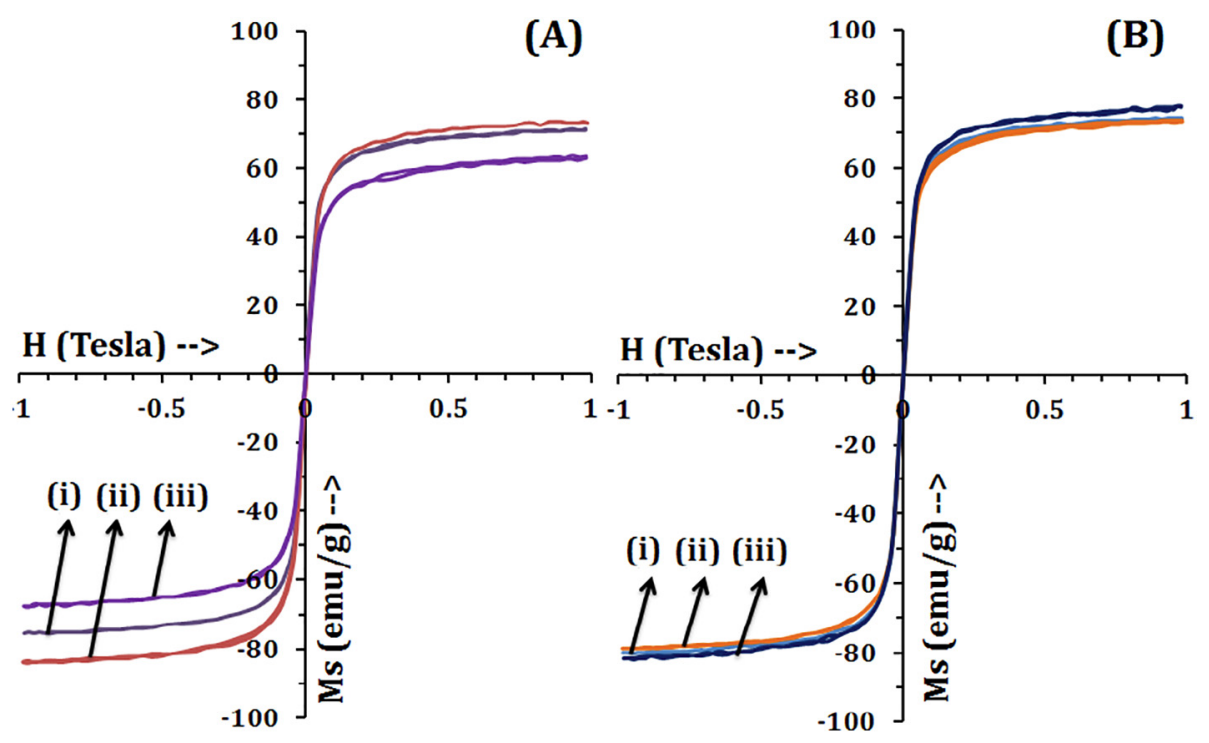

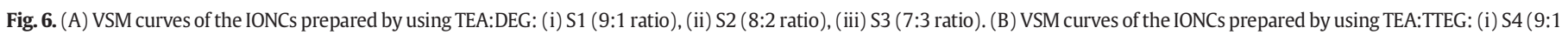
ratio), (ii) S5 (8:2 ratio), (iii) S6 ( 7:3 ratio).

planes indicating the magnetite $\left(\mathrm{Fe}_{3} \mathrm{O}_{4}\right)$ phase with cubic inverse spinel structure (as confirmed via 19-0629 JCPDS file), which corroborates with their SAEDP results (Fig. 3B (iii)). Similarly, the XRD results for other IONCs samples can be acquired.

\subsection{Type of surface coatings - FTIR}

Fig. 4A (i-iii), and B (i-iii) shows the FTIR spectra of the S1-S3, and S4-S6 samples prepared at 9:1, 8:2 and 7:3 ratios of TEA:DEG, and TEA:
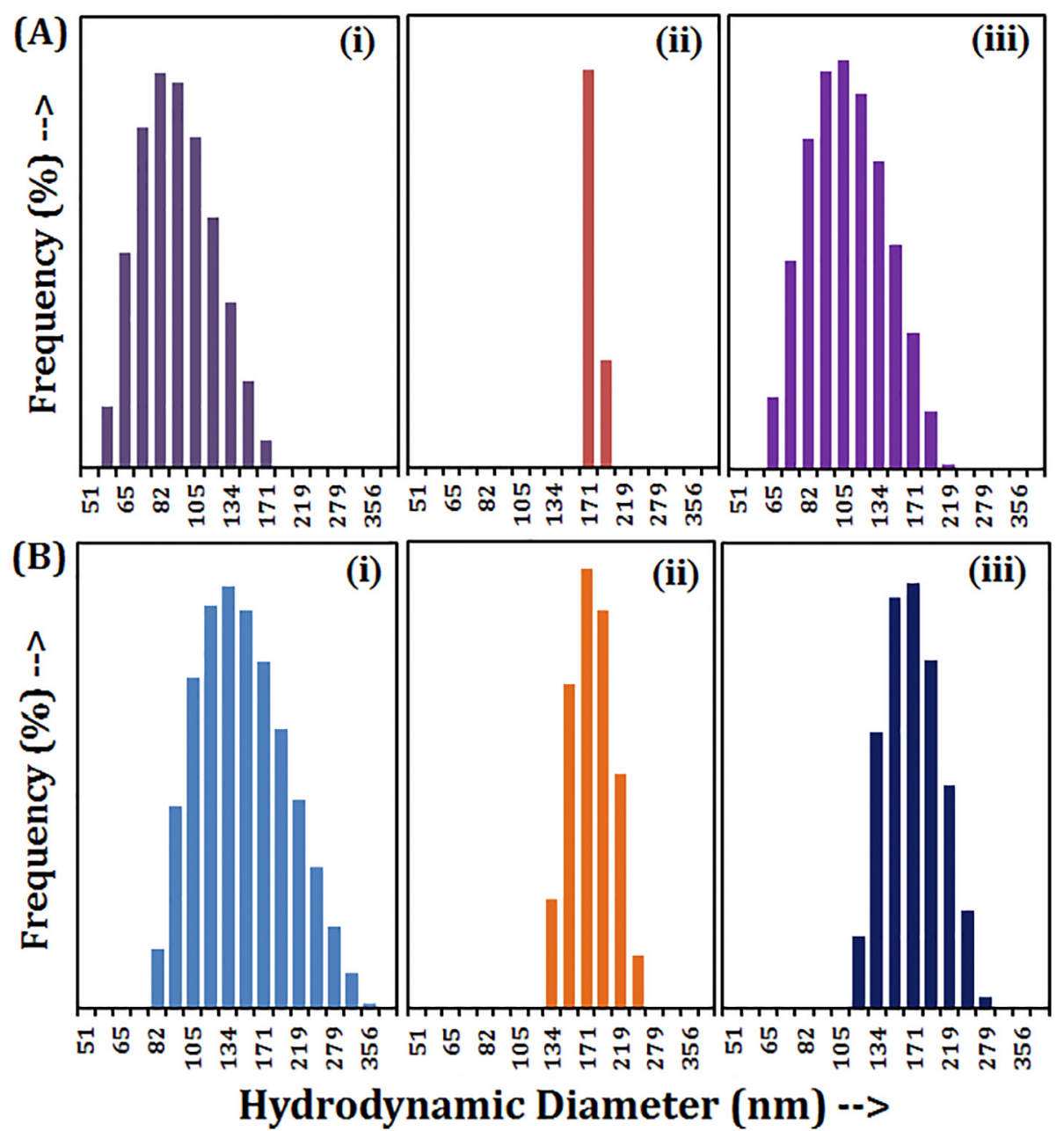

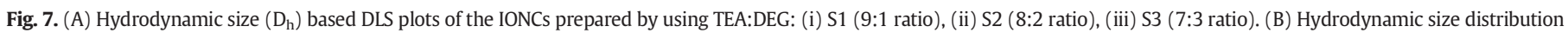
plots of the IONCs prepared by using TEA:TTEG: (i) S4 (9:1 ratio), (ii) S5 ( 8:2 ratio), (iii) S6 (7:3 ratio). 
Table 2

Mean hydrodynamic diameter (in $\mathrm{nm}$ ) and zeta potential values (in $\mathrm{mV}$ ) of the as-prepared IONCs (S1-S6 samples) and MNC-14 nanoclusters.

\begin{tabular}{lcc}
\hline Sample code & Mean hydrodynamic size $(\mathrm{nm})$ & Mean zeta potential $(\mathrm{mV})$ \\
\hline S1 & $95.3 \pm 0.5$ & +48.2 \\
S2 & $168.1 \pm 11.9$ & +55.0 \\
S3 & $125.3 \pm 6.4$ & +57.8 \\
S4 & $141.3 \pm 4.9$ & +46.9 \\
S5 & $177.5 \pm 3.3$ & +52.9 \\
S6 & $191.9 \pm 1.1$ & +65.2 \\
MNC-14 & $164.7 \pm 7.4$ & +30.0 \\
\hline
\end{tabular}

TTEG, respectively. The absorption peaks at about $590 \mathrm{~cm}^{-1}$ are ascribed to the $\mathrm{Fe}-\mathrm{O}$ stretching bands, which are due to the magnetite cores of all the IONCs samples (as confirmed by the SAEDP and XRD results). Moreover, the absorption peaks at about 2963-2801/2967$2821 \mathrm{~cm}^{-1}, \quad 1696-1491 / 1701-1483 \mathrm{~cm}^{-1}, \quad 1486-1353 / 1477-$ $1349 \mathrm{~cm}^{-1}, 1030-1043 / 1022-1032 \mathrm{~cm}^{-1}$, and 867-879/894$899 \mathrm{~cm}^{-1}$ are attributed to the $\mathrm{C}-\mathrm{H}$ stretching, $\mathrm{N}-\mathrm{H}$ bending, $\mathrm{C}-\mathrm{H}$ bending, $\mathrm{C}-\mathrm{O}$ stretching and $\mathrm{O}-\mathrm{H}$ bending vibrations, that are corresponded to the polyols (i.e. DEG/TTEG) and TEA molecules attached to the surface of the iron oxide cores. Thus, the FTIR spectra confirm the presence of DEG/TTEG/TEA surface coating molecules for all the as-prepared IONCs.

\subsection{Amount of surface coatings - TGA}

Fig. 5A (i-iii), and B (i-iii) displays the TGA curves of the S1-S3, and S4-S6 samples prepared at 9:1, 8:2 and 7:3 ratios of TEA:DEG, and TEA: TTEG, respectively. In TGA curves, major weight-losses (in \%) has occurred in two temperature regions. First weight loss has occurred in the temperature region of $30-200{ }^{\circ} \mathrm{C}$, and second weight loss has occurred in the temperature region of $\sim 201-800{ }^{\circ} \mathrm{C}$ due to decomposition of the physically adsorbed water molecules and chemically adsorbed surface coating (i.e. TEA-DEG/TEA-TTEG) molecules, respectively. The amount of the surface coatings (in \%) are estimated and given in Table 1.

It can be noted that the amounts of TEA-DEG and TEA-TTEG coating molecules are in the range of 11-12 and 7-11 wt\% for S1-S3 and S4-S6 samples, respectively. In addition, the corresponding amount of TEADEG surface coatings are found to be slightly higher than the TEATTEG surface coatings, which could be mainly due to the smaller size (larger surface area) of the TEA-DEG coated IONCs (i.e. S1-S3 samples) as compared to the TEA-TTEG coated IONCs (i.e. S4-S6 samples). Moreover, the amount the TEA-DEG/TEA-TTEG surface coatings of the corresponding IONCs (8:2 TEA:DEG/TEA:TTEG) are found to be higher than the amount of the TEA-TEG surface coatings ( $9 \mathrm{wt} \%$ ) of the reported MNC-14 nanoclusters (8:2 TEA:TEG), which could be due to their larger size (smaller surface area) as compared to the TEA-DEG/TEA-TTEG coated S2/S5 sample (refer Table 1).
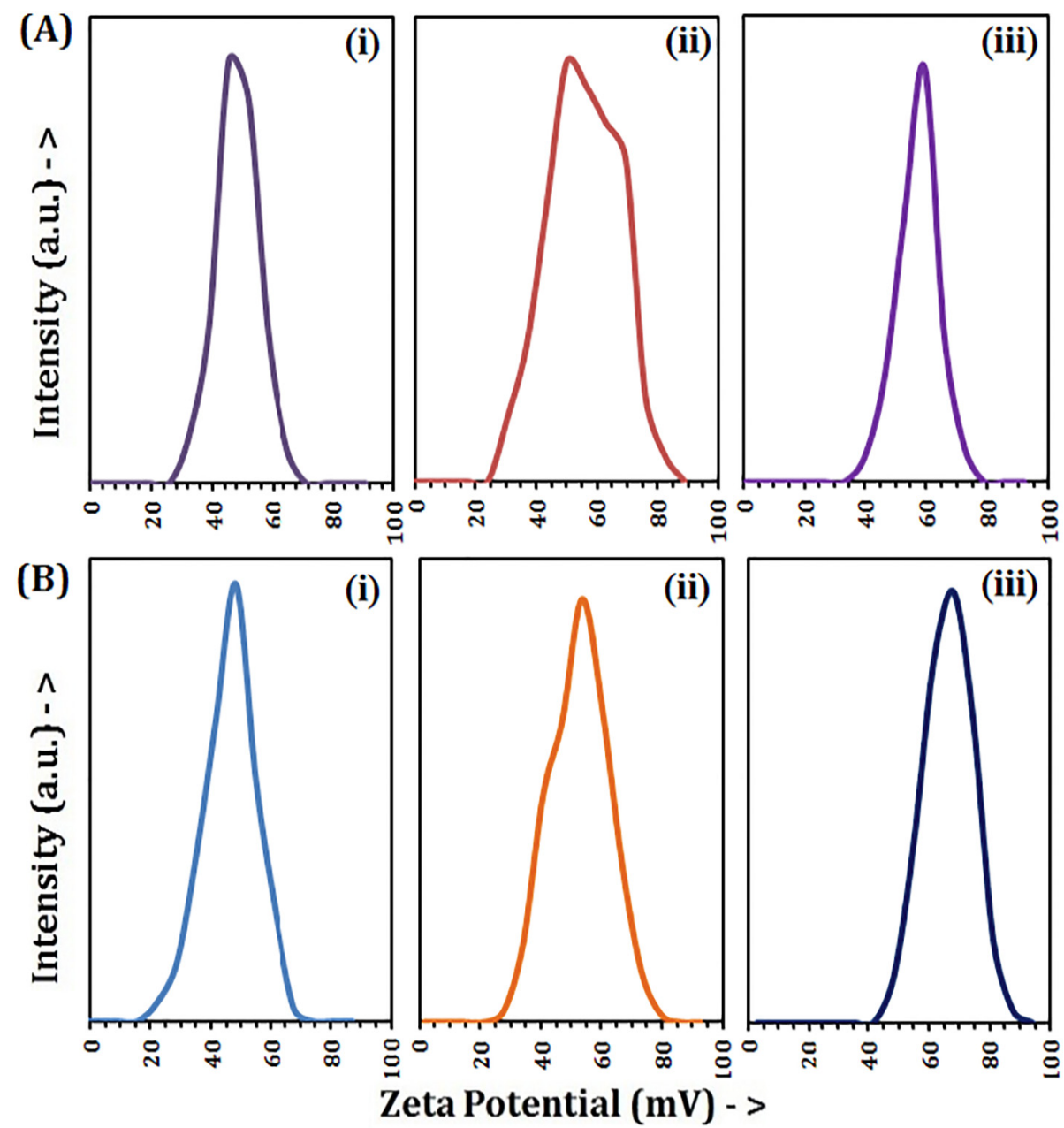

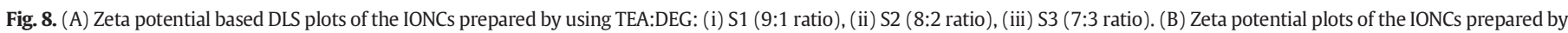
using TEA:TTEG: (i) S4 (9:1 ratio), (ii) S5 (8:2 ratio), (iii) S6 (7:3 ratio). 


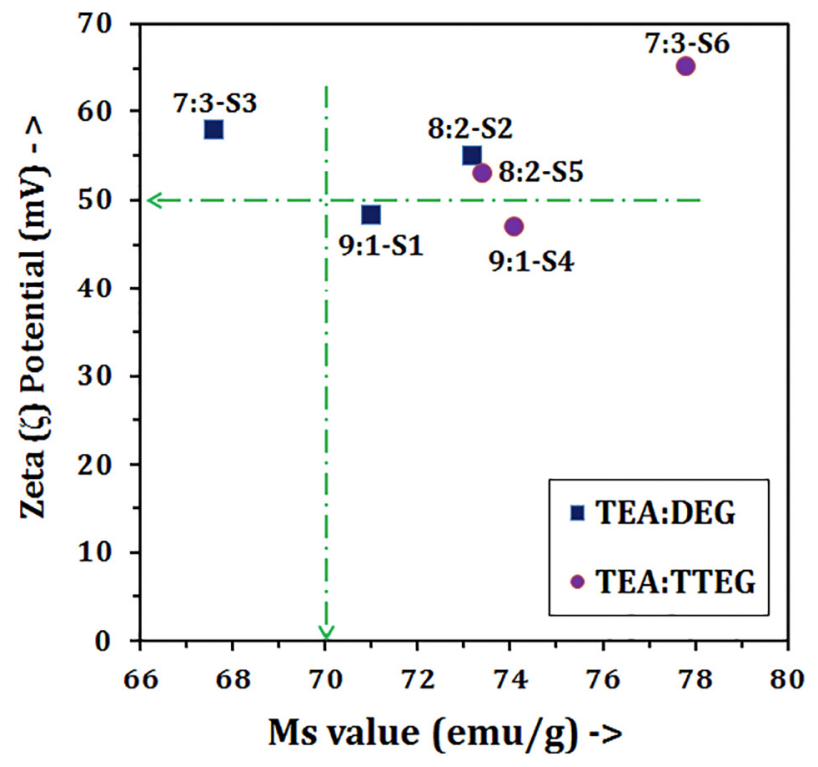

Fig. 9. Magnetization (Ms) vs zeta $(\zeta)$ potential plot of the samples of IONCs prepared using TEA:DEG (9:1-S1, 8:2-S2, and 7:3-S3), and TEA:TTEG (9:1-S4, 8:2-S5, and 7:3-S6).

\subsection{Magnetization (M-H) - VSM}

Fig. 6A (i-iii), and B (i-iii) depicts the magnetization (M-H) curves of the S1-S3, and S4-S6 samples prepared at 9:1, 8:2 and 7:3 ratios of TEA: DEG, and TEA:TTEG, respectively. Zero remanence and zero coercivity confirm the superparamagnetic character of all the as-prepared IONCs [41]. The saturation magnetization (Ms) values of the S1, S2, S3, S4, S5, and S6 samples are determined as 71, 73.2, 67.6, 74.1, 73.4 and $77.8 \mathrm{emu} / \mathrm{g}$ respectively. It can be seen that the Ms. values of the TEATTEG coated IONCs (i.e. S4-S6 samples) are relatively higher than the TEA-DEG coated IONCs (i.e. S1-S3 samples), which could be mainly due to the bigger size and lower amount of non-magnetic surface coatings of the TEA-TTEG coated IONCs (than the TEA-DEG coated IONCs) as confirmed via TEM and TGA, respectively (refer Table 1 ). Moreover, the sample S6 (7:3 TEA:TTEG) has demonstrated highest Ms. value (i.e. $77.8 \mathrm{emu} / \mathrm{g}$ ), which is even higher than the Ms. value (i.e., $75 \mathrm{emu} / \mathrm{g}$ ) of our previously reported MNC-14 nanoclusters, which could be due to their improved crystallinity/lower amount of nonmagnetic surface coatings - as confirmed via TEM/TGA results.

\subsection{Dispersibility and water solubility - DLS}

\subsubsection{Hydrodynamic diameter}

Fig. 7A (i-iii), and B (i-iii) represents the DLS plots of the S1-S3, and S4-S6 samples prepared at 9:1, 8:2 and 7:3 ratios of TEA:DEG, and TEA: TTEG, respectively. A unimodal distribution in the hydrodynamic diameters $\left(D_{h}\right)$ is obtained for all the IONCs samples dispersed in their aqueous ferrofluids (AFFs) suspensions and the corresponding $D_{h}$ values (by taking the average of three values) are given in Table 2 . The mean $D_{h}$ values are determined as $95.3 \pm 0.5 \mathrm{~nm}, 168.1 \pm 11.9 \mathrm{~nm}$, $125.3 \pm 6.4 \mathrm{~nm}, 141.3 \pm 4.9 \mathrm{~nm}, 177.5 \pm 3.3 \mathrm{~nm}$ and $191.9 \pm 1.1 \mathrm{~nm}$ for the S1, S2, S3, S4, S5 and S6 samples, respectively. The $D_{h}$ values of the TEA-TTEG coated IONCs (i.e. S4-S6 samples) are found to be larger than the TEA-DEG coated IONCs (i.e. S1-S3 samples), which could be mainly due to the impact of the longer-chain length of the TTEG molecules as compared to the shorter-chain length of the DEG molecules.

Moreover, the $D_{h}$ value of the as-synthesized TEA-TEG coated MNC14 nanoclusters is determined as $164.7 \pm 7.4 \mathrm{~nm}$, which is slightly lower than the $D_{h}$ values (i.e. $168.1 \pm 11.9$ and $177.5 \pm 3.3 \mathrm{~nm}$ ) of the corresponding TEA-DEG/TEA-TTEG coated IONCs (8:2 TEA:DEG/ TEA:TTEG). However, the $D_{h}$ values of all the IONCs are found to be higher than their average TEM particle sizes, that is mostly attributed to the small aggregate formations in their AFFs suspension due to the magnetic dipole-dipole interactions [42].

\subsubsection{Zeta potential}

Fig. 8A (i-iii), and B (i-iii) depicts the zeta $(\zeta)$ potential based DLS plots of the S1-S3, and S4-S6 samples prepared at 9:1, 8:2 and 7:3 ratios of TEA:DEG, and TEA:TTEG, respectively. The corresponding maximum $\zeta$ potential values (by taking average of three values) of the waterdispersed samples are given in Table 2 . The mean $\zeta$ potential values are quantified as $+48.2,+55,+57.8,+46.9,+52.9$ and $+65.2 \mathrm{mV}$ for the S1, S2, S3, S4, S5 and S6 samples, respectively. Herein, the $\zeta$ potential values are increased with the amount of polyol (DEG/TTEG) used in liquid mixtures during the synthesis (i.e., from 9:1 to 7:3 TEA:DEG/TEA: TTEG), and the highest $\zeta$ potential value of $+65.2 \mathrm{mV}$ is obtained for the IONCs prepared at 7:3 TEA:TTEG ratio (i.e. S6 samples). It can be seen that, the $\zeta$ potential value (i.e., $+30 \mathrm{mV}$ ) of the MNC-14 nanoclusters is found to be much lower than the $\zeta$ potential values (i.e. +46.9 to $+65.2 \mathrm{mV}$ ) of all the IONCs. In general, stable water suspension of particles might have $\zeta$ potential values more than $\pm 30 \mathrm{mV}$ $[43,44]$. Therefore, the as-prepared TEA-DEG/TTEG coated IONCs are highly water-soluble and very much stable in their AFFs suspension as compared to the TEA-TEG coated MNC-14 nanoclusters.

Based on the above discussions, the S2, S5 and S6 samples (i.e. IONCS prepared at ratios - 8:2 TEA:DEG, 8:2 TEA:TTEG, and 7:3 TEA:TTEG, respectively) displayed comparatively higher magnetization values (above $70 \mathrm{emu} / \mathrm{g}$ ) and better water solubility ( $\zeta$ above $+50 \mathrm{mV}$ ) as shown in Fig. 9. Hence, the S2, S5 and S6 samples based AFFs (labelled as NCAFF-1, NCAFF-2, and NCAFF-3, respectively) are selected for subsequent investigations through MFH studies.

\subsection{Calorimetric MFH studies}

Herein, the calorimetric studies are performed to investigate the time dependent temperature rise of the selected NCAFFs to a fixed $42{ }^{\circ} \mathrm{C}$ (i.e., minimum temperature required for cancer hyperthermia therapeutics) after exposing them to the AMFs, and subsequently to evaluate their heating efficacies in terms of SAR $\left(\mathrm{W} / \mathrm{g}_{\mathrm{Fe}}\right)$ and ILP $\left(\mathrm{nHm}^{2} / \mathrm{kg}\right)$ which represents the power dissipation.

Table 3

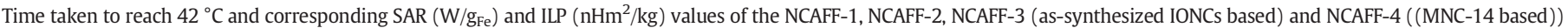
exposed to the AMFs $\left(\mathrm{H}^{*} \mathrm{f}=\sim 8.2 \mathrm{GA} \mathrm{m}^{-1} \mathrm{~s}^{-1}\right)$ at different concentrations $(\phi=0.5-8 \mathrm{mg} / \mathrm{ml})$.

\begin{tabular}{|c|c|c|c|c|c|c|c|c|c|c|c|c|}
\hline \multirow{2}{*}{$\begin{array}{l}\phi(\text { in } \\
\mathrm{mg} / \mathrm{ml})\end{array}$} & \multicolumn{3}{|c|}{ NCAFF-1 } & \multicolumn{3}{|c|}{ NCAFF-2 } & \multicolumn{3}{|c|}{ NCAFF-3 } & \multicolumn{3}{|c|}{ NCAFF-4 } \\
\hline & $\begin{array}{l}\mathrm{TP} \text { (in } \\
\min )\end{array}$ & $\begin{array}{l}\text { SAR } \\
\left(\mathrm{W} / \mathrm{g}_{\mathrm{Fe}}\right)\end{array}$ & $\begin{array}{l}\text { ILP } \\
\left(\mathrm{nHm}^{2} / \mathrm{kg}\right)\end{array}$ & $\begin{array}{l}\mathrm{TP} \text { (in } \\
\min )\end{array}$ & $\begin{array}{l}\text { SAR } \\
\left(\mathrm{W} / \mathrm{g}_{\mathrm{Fe}}\right)\end{array}$ & $\begin{array}{l}\text { ILP } \\
\left(\mathrm{nHm}^{2} / \mathrm{kg}\right)\end{array}$ & $\begin{array}{l}\mathrm{TP} \text { (in } \\
\min )\end{array}$ & $\begin{array}{l}\text { SAR } \\
\left(\mathrm{W} / \mathrm{g}_{\mathrm{Fe}}\right)\end{array}$ & $\begin{array}{l}\text { ILP } \\
\left(\mathrm{nHm}^{2} / \mathrm{kg}\right)\end{array}$ & $\begin{array}{l}\text { TP (in } \\
\text { min) }\end{array}$ & $\begin{array}{l}\text { SAR } \\
\left(\mathrm{W} / \mathrm{g}_{\mathrm{Fe}}\right)\end{array}$ & $\begin{array}{l}\text { ILP } \\
\left(\mathrm{nHm}^{2} / \mathrm{kg}\right)\end{array}$ \\
\hline$\phi_{1}=0.5$ & 12.5 & 693.4 & 7.7 & 11.7 & 530.9 & 5.9 & 9.7 & 847.4 & 9.4 & 14.1 & 418.7 & 4.6 \\
\hline$\phi_{2}=1$ & 5.3 & 432.5 & 4.8 & 5.2 & 423.7 & 4.7 & 5.7 & 464.3 & 5.2 & - & - & - \\
\hline$\phi_{3}=2$ & 2.6 & 288.1 & 3.2 & 2.4 & 293.7 & 3.3 & 2.6 & 297.5 & 3.3 & - & - & - \\
\hline$\phi_{4}=4$ & 1.9 & 175.7 & 2 & 1.5 & 166.1 & 1.8 & 1.3 & 221.9 & 2.5 & - & - & - \\
\hline$\phi_{5}=8$ & 1.3 & 96.1 & 1.1 & 1.2 & 109.2 & 1.2 & 0.7 & 164 & 1.8 & - & - & - \\
\hline
\end{tabular}

Where, TP - Time Period. 
Initially, to investigate the influence of particle concentrations $(\phi)$, the NCAFF-1, NCAFF- 2 and NCAFF-3 are exposed to the AMF $\left(\mathrm{H}^{*} \mathrm{f}=\right.$ $\left.\sim 8.2 \mathrm{GA} \mathrm{m}^{-1} \mathrm{~s}^{-1}\right)$ at different concentrations $(\phi=0.5-8 \mathrm{mg} / \mathrm{ml})$ and the time dependent temperature graphs (i.e. heating curves) are plotted and the corresponding SAR/ILP values are determined (refer Table 3).
Fig. 10A, B and $\mathrm{C}$ depicts the respective heating curves of NCAFF-1, NCAFF-2, and NCAFF-3 at concentrations of $0.5-8 \mathrm{mg} / \mathrm{ml}\left(\phi_{1}-\phi_{5}\right)$. Moreover, Fig. 10D (i) portrays the concentrations vs time graph, which shows the time taken by these NCAFFs to attain $42{ }^{\circ} \mathrm{C}$, and Fig. 10D (ii) represents the concentrations vs SAR values (heating
A

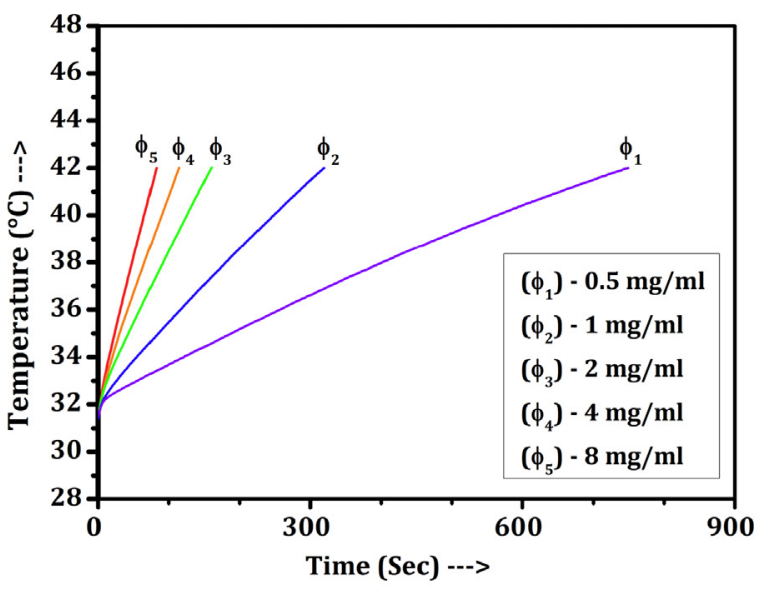

C

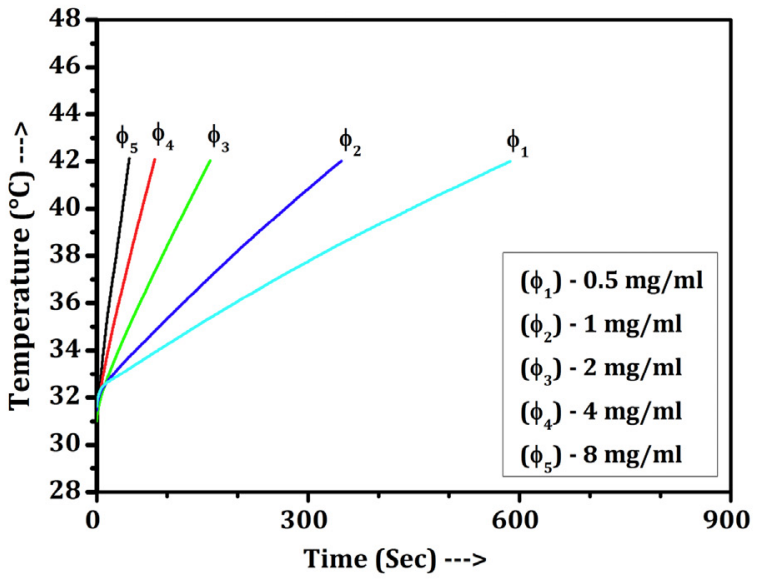

$\mathbf{E}$

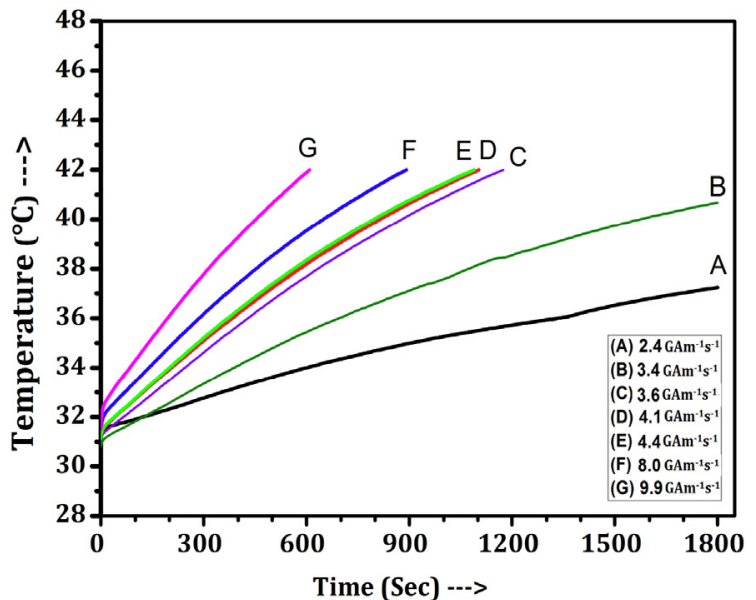

B

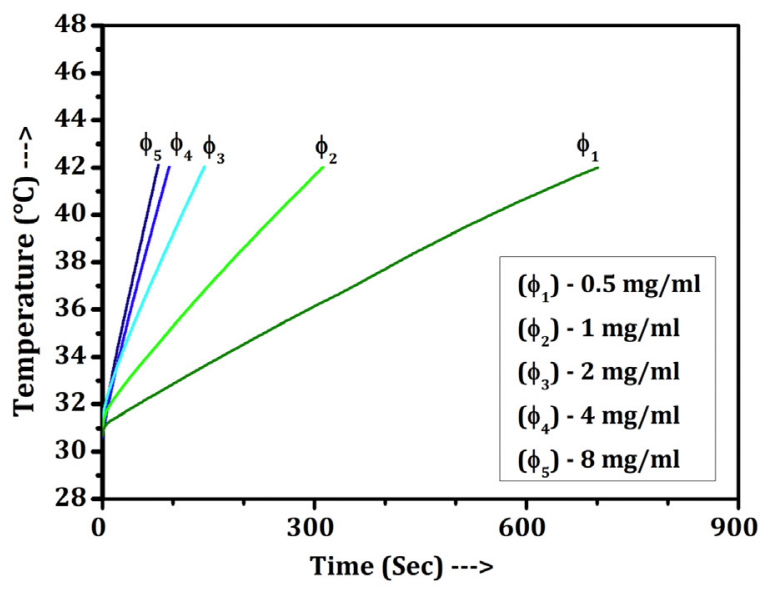

D
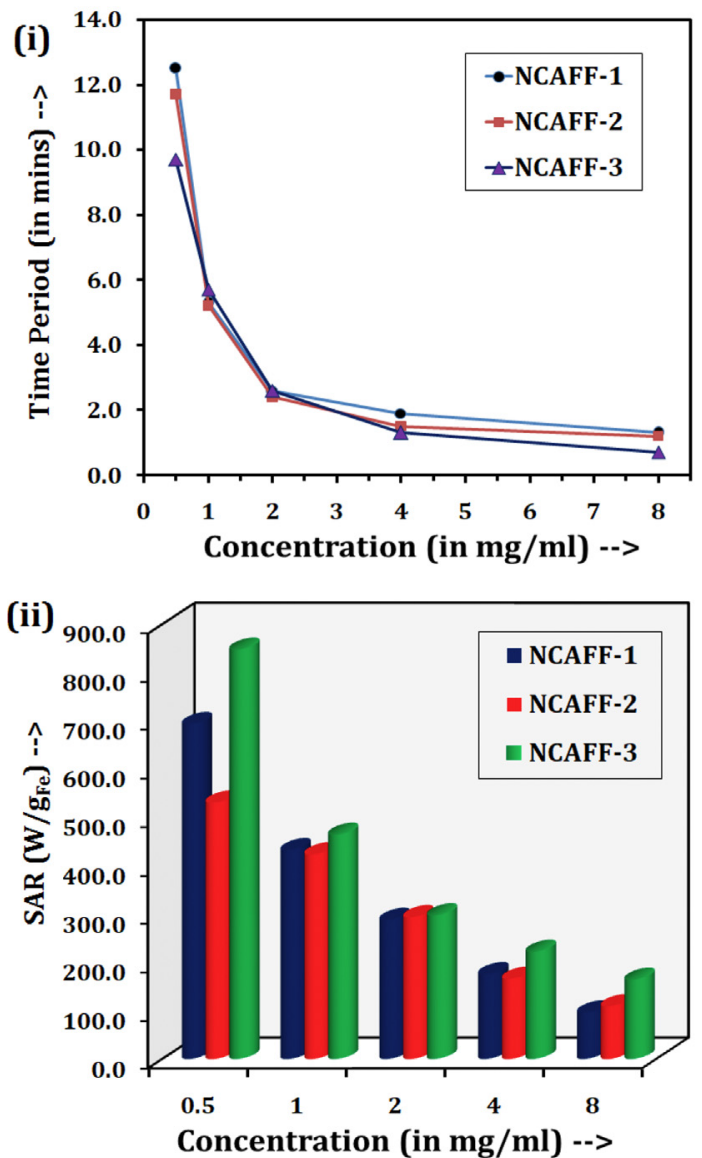

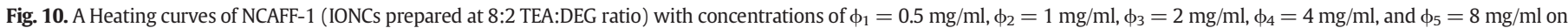

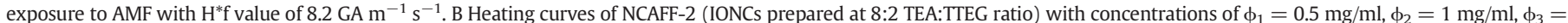

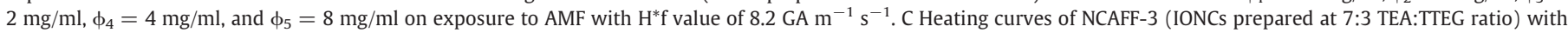

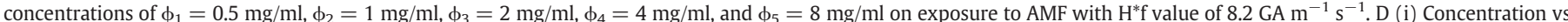

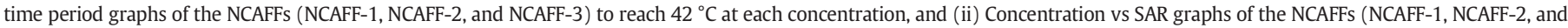

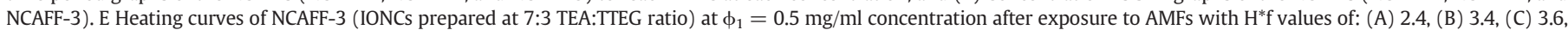
(D) 4.1, (E) 4.4, (F) 8.0 and (G) $9.9 \mathrm{GA} \mathrm{m}^{-1} \mathrm{~s}^{-1}$. 
Table 4

Time taken to reach $42^{\circ} \mathrm{C}$ and corresponding SAR $\left(\mathrm{W} / \mathrm{g}_{\mathrm{Fe}}\right)$ and ILP $(\mathrm{nHm} / \mathrm{kg})$ values of the NCAFF-3 (i.e. $\mathrm{S} 6$ based AFFs) on exposure to different magnetic fields ( $\mathrm{H}^{*} \mathrm{f}=\sim 2.44$ $\left.9.99 \mathrm{GA} \mathrm{m}^{-1} \mathrm{~s}^{-1}\right)$ at a concentration $\left(\phi_{1}\right)$ of $0.5 \mathrm{mg} / \mathrm{ml}$.

\begin{tabular}{lccccc}
\hline $\begin{array}{l}\mathrm{H}^{*} \mathrm{f}\left(\text { in } \mathrm{GA} \mathrm{m}^{-1}\right. \\
\left.\mathrm{s}^{-1}\right)\end{array}$ & $\begin{array}{l}\mathrm{f}(\text { in } \\
\mathrm{kHz})\end{array}$ & $\begin{array}{l}\mathrm{H}(\text { in } \\
\mathrm{kA} / \mathrm{m})\end{array}$ & $\begin{array}{l}\mathrm{TP}(\text { in } \\
\mathrm{min})\end{array}$ & $\begin{array}{l}\mathrm{SAR}(\text { in } \\
\left.\mathrm{W} / \mathrm{g}_{\mathrm{Fe}}\right)\end{array}$ & $\begin{array}{l}\text { ILP (in } \\
\mathrm{nHm} / \mathrm{kg})\end{array}$ \\
\hline 2.4 & 175.2 & 13.9 & $\mathrm{NR}$ & 142.4 & 4.2 \\
3.4 & 330.3 & 10.3 & $\mathrm{NR}$ & 324.1 & 9.1 \\
3.6 & 262.2 & 13.8 & 19.5 & 273.0 & 5.5 \\
4.1 & 474.7 & 8.6 & 18.3 & 330.8 & 9.3 \\
4.4 & 632.3 & 7.1 & 18.1 & 467.3 & 14.7 \\
8.0 & 522.2 & 15.3 & 14.8 & 550.2 & 4.4 \\
8.2 & 751.5 & 10.9 & 9.7 & 847.4 & 9.4 \\
9.9 & 1001.1 & 9.9 & 9.5 & 909.4 & 9.1 \\
\hline
\end{tabular}

Where, TP - time period, and NR - Not Reached to $42{ }^{\circ} \mathrm{C}$.

efficacies) of the AFFs. It can be observed that the time taken by all the NCAFFs is gradually decreased with the increase in their concentrations (i.e. increase in magnetic Fe element) from $\phi_{1}$ to $\phi_{5}$, which is an obvious physical phenomenon (refer Table 3). However, the SAR values are also decreased with the increment of their concentrations, ascribed to the increased inter-particle/magnetic dipole-dipole interactions (i.e. aggregations) among the nanoclusters at higher concentrations. Nevertheless, the highest SAR/ILP value of $847.4 \mathrm{~W} / \mathrm{g}_{\mathrm{Fe}} / 9.4 \mathrm{nHm} / \mathrm{kg}$ is attained for the NCAFF-3 (at $\phi_{1}=0.5 \mathrm{mg} / \mathrm{ml}$ concentration). Moreover, the calorimetric MFH experiments of the NCAFF-4 (MNC-14 based AFFs) are performed at $\phi_{1}=0.5 \mathrm{mg} / \mathrm{ml}$ concentration by applying AMF of 8.2 GA m ${ }^{-1} \mathrm{~s}^{-1}$. The SAR/ILP values of the NCAFF-4 are measured as $418.7 \mathrm{~W} / \mathrm{g}_{\mathrm{Fe}} / 4.6 \mathrm{nHm}^{2} / \mathrm{kg}$ - which are much lower than those values of the NCAFF-3 (refer Tables 1/S1). Thus, the NCAFF-3 has demonstrated enhanced heating efficiencies (power dissipation) as compared to the NCAFF-1, NCAFF-2, NCAFF-4 for all the concentrations, which could be attributed to the lower amount of surface coatings, higher Ms. value, larger $\mathrm{D}_{\mathrm{h}}$ and higher water solubility of the IONCs (i.e. S6 sample) as evidenced from the TGA, VSM, and DLS results, respectively.

Based on the above discussions, the NCAFF-3 is further selected to investigate the influence of the magnetic fields and Fig. 10E depicts the heating curves of the NCAFF-3 (at $\phi_{1}=0.5 \mathrm{mg} / \mathrm{ml}$ ) on exposure to a broad range of AMFs with $\mathrm{H}^{*}$ f values 2.4-9.9 $\mathrm{GA} \mathrm{m}^{-1} \mathrm{~s}^{-1}$ (close to BPSL $-5 \mathrm{GA} \mathrm{m}^{-1} \mathrm{~s}^{-1}$ ). The time taken by the NCAFF-3 to reach at $42{ }^{\circ} \mathrm{C}$, and the corresponding SAR/ILP values are given in Table 4 . It can be observed that the temperature of the NCAFF- 3 has not reached to $42{ }^{\circ} \mathrm{C}$ for the $\mathrm{H}^{*} \mathrm{f}$ values of $2.4-3.4 \quad \mathrm{GA} \mathrm{m}^{-1} \mathrm{~s}^{-1}$ (i.e., $\leq 3.4 \mathrm{GA} \mathrm{m}^{-1} \mathrm{~s}^{-1}$ ) within the stipulated time periods of $30 \mathrm{~min}$, while the temperature has reached to $42{ }^{\circ} \mathrm{C}$ for the $\mathrm{H}^{*} \mathrm{f}$ values of 3.6-9.9 GA m ${ }^{-1} \mathrm{~s}^{-1}$ (i.e., $3.4 \mathrm{GA} \mathrm{m}^{-1} \mathrm{~s}^{-1}$ ) within the time periods of ranging from 9.5-19.5 min. However, the time required to reach the

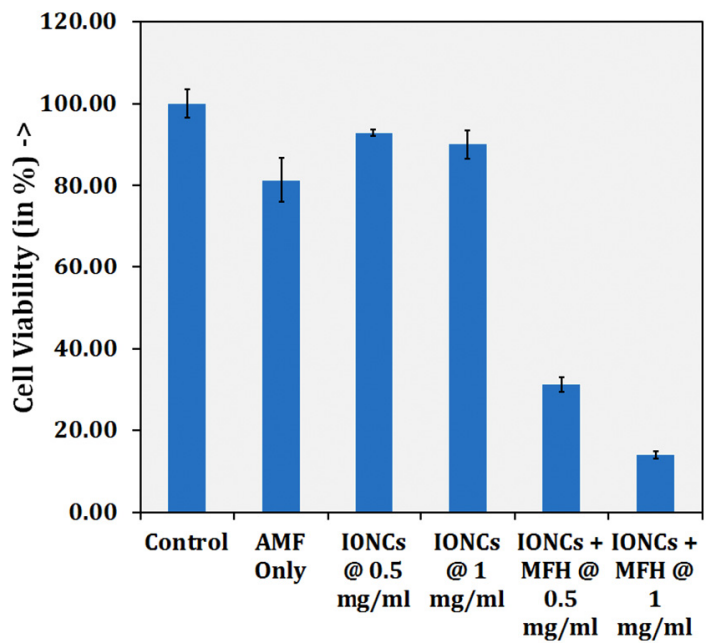

Fig. 11. Cell viability plot depicts the cytotoxic effect on HepG2 cancer cells treated with MFH $\left(\sim 42{ }^{\circ} \mathrm{C}\right)$ by using the IONCs (prepared at 7:3 TEA:TTEG ratio - S6) at 0.5 and $1 \mathrm{mg} / \mathrm{ml}$ concentrations on exposure to AMF (with $\mathrm{H}^{*}$ f value of $8.2 \mathrm{GA} \mathrm{m}^{-1} \mathrm{~s}^{-1}$ ) as compared to control, cells treated with only magnetic field (i.e., without IONCs), and cells incubated with only IONCs (at 0.5 and $1 \mathrm{mg} / \mathrm{ml}$ concentrations - without AMF).

fixed temperature $\left(\leq 42{ }^{\circ} \mathrm{C}\right)$ is gradually reduced and the corresponding SAR values are increased (from $142.4 \mathrm{~W} / \mathrm{g}_{\mathrm{Fe}}$ to $909.4 \mathrm{~W} / \mathrm{g}_{\mathrm{Fe}}$ ) as the $\mathrm{H}^{*} \mathrm{f}$ values of the AMFs are increased from $2.4 \mathrm{GA} \mathrm{m}^{-1} \mathrm{~s}^{-1}$ to 9.9 GA m ${ }^{-1} \mathrm{~s}^{-1}$ (refer Table 4). Besides, the NCAFF-3 has shown the ILP values in the range of $4.2 \mathrm{nHm}^{2} / \mathrm{kg}$ to $14.7 \mathrm{nHm}^{2} / \mathrm{kg}$ for the applied AMFs ( $\mathrm{H}^{*} \mathrm{f} \sim 2.4-9.9 \mathrm{GA} \mathrm{m}^{-1} \mathrm{~s}^{-1}$ ), and the highest ILP value (i.e. $14.7 \mathrm{nHm}^{2} / \mathrm{kg}$ ) is attained at the $\mathrm{H}^{*} \mathrm{f}$ value of $4.4 \mathrm{GA} \mathrm{m}^{-1} \mathrm{~s}^{-1}$ (near to BPSL). Moreover, the ILP values of the NCAFF-3 are comparatively higher than those reported values of the flower-shaped magnetic nanoclusters (refer Table 5) [26,29,30,33].

Finally, to investigate the influence of dispersion media, the S6 samples (i.e. IONCs prepared using 7:3 ratio of TEA:TTEG that have showed higher heating efficacy) are dispersed in different biological media such as DMEM, FBS, DMEM + 5\%FBS, and PBS to form IONCs based biological ferrofluids (NCBFFs - labelled as NCBFF-1, NCBFF-2, NCBFF-3, and NCBFF-4, respectively). The NCBFFs (at $\phi_{1}=0.5 \mathrm{mg} / \mathrm{ml}$ concentration) are exposed to the AMF $\left(\mathrm{H}^{*} \mathrm{f}=\sim 8.2 \mathrm{GA} \mathrm{m}^{-1} \mathrm{~s}^{-1}\right)$ and the results including the heating curves and the SAR/ILP values are given in the Supplementary data. Fig. $\mathrm{S} 1$ shows the time-dependent temperature rise of the NCBFFs (i.e. NCBFF-1, NCBFF-2, NCBFF-3, and NCBFF-4) and the required time to reach at $42{ }^{\circ} \mathrm{C}$ and corresponding SAR/ILP values are given in Table S1. It can be seen that the required time (i.e. 14.5, 11.4,

Table 5

Comparison of the as-prepared flower-shaped IONCs based AFFs (i.e., NCAFF-3) with the reported magnetic nanoclusters based AFFs.

\begin{tabular}{|c|c|c|c|c|c|c|c|c|}
\hline Precursors & TEM Particle Size (nm) & $\begin{array}{l}\mathrm{H} \\
(\mathrm{kA} / \mathrm{m})\end{array}$ & $\mathrm{f}(\mathrm{kHz})$ & $\begin{array}{l}\mathrm{H}^{*} \mathrm{f}(\mathrm{GA} \\
\mathrm{m}^{-1} \\
\left.\mathrm{~s}^{-1}\right)\end{array}$ & $\begin{array}{l}\text { SAR } \\
\left(\mathrm{W} / \mathrm{g}_{\mathrm{Fe}}\right)\end{array}$ & $\begin{array}{l}\text { ILP } \\
\left(\mathrm{nHm}{ }^{2} / \mathrm{kg}\right)^{*}\end{array}$ & Year & Ref \\
\hline $\mathrm{NMDEA}^{\mathrm{a}} \& \mathrm{DEG}$ & 12.7 & - & - & - & - & - & 2004 & [25] \\
\hline TEA \& TEG & 44 & 89 & 240 & 21.4 & $\sim 500$ & $0.3^{*}$ & 2011 & [33] \\
\hline NMDEA \& DEG & 24 & 21.5 & 700 & 15.05 & 1992 & $6.2^{*}$ & 2012 & [26] \\
\hline NMDEA \& DEG & 24.9 & 25 & 700 & 17.5 & $\sim 2000$ & $4.6^{*}$ & 2012 & [29] \\
\hline NMDEA \& DEG & $\sim 37$ & 10.2 & 755 & 7.7 & 296 & $3.8^{*}$ & 2017 & {$[30]$} \\
\hline $\begin{array}{l}\mathrm{NMDEA} \& \mathrm{DEG}, \mathrm{EG}^{\mathrm{b}} \& \text { citric acid, and } \mathrm{NaBH}_{4}{ }^{\mathrm{c}} \& \mathrm{THF}^{\mathrm{d}} / \text { water } \\
\text { mixture }\end{array}$ & $\begin{array}{l}47,110 \text { and } 24, \\
\text { respectively }\end{array}$ & - & - & - & - & - & 2017 & [31] \\
\hline TEA \& TTEG & 29 & $7.1-15.3$ & $175.2-1001.1$ & $2.4-9.9$ & $142-909$ & $4.2-14.7$ & 2018 & $\begin{array}{l}\text { This } \\
\text { work }\end{array}$ \\
\hline
\end{tabular}

Where,

a NMDEA - N-methyl diethanolamine.

b EG - ethylene glycol.

c $\mathrm{NaBH}_{4}$ - sodium borohydride.

d THF - tetrahydrofuran.

* Calculated based on the values reported in literatures. 
12.4, and $13.8 \mathrm{~min}$ ) are found to be higher than the time required by their aqueous ferrofluid counterpart - NCAFF-3 (i.e. 9.7 min) at similar concentration/AMF. It can also be seen that the SAR values (i.e. 633.9, 652.3, 579.5, 571.9 W/gFe) and ILP values (i.e. 7.0, 7.2, 6.4 and $6.3 \mathrm{nHm}^{2} / \mathrm{kg}$ ) of the NCBFFs are comparatively smaller than those values (i.e. $847.4 \mathrm{~W} / \mathrm{gFe}$ and $9.4 \mathrm{nHm}^{2} / \mathrm{kg}$ ) of the NCAFF-3. This indicates that the IONCs based biological ferrofluids (i.e., NCBFFs) have relatively lower heating efficacies as compared to the aqueous ferrofluids (i.e. NCAFFs) which could be attributed to the complex interactions between the surface of the IONCs and the molecules suspended in the biological liquids [45-47].

Thus, the NCAFF-3 (S6 sample based ferrofluids) has displayed enhanced heating effects, and hence selected for further studies.

\subsection{In vitro cytocompatibility and cell uptake studies}

The cytocompatibility of the IONCs (S6/NCAFF-3 - at concentrations from 5 to $25 \mu \mathrm{g}_{\mathrm{Fe}}$ per well) in HepG2 cells at 24/48 h incubation time

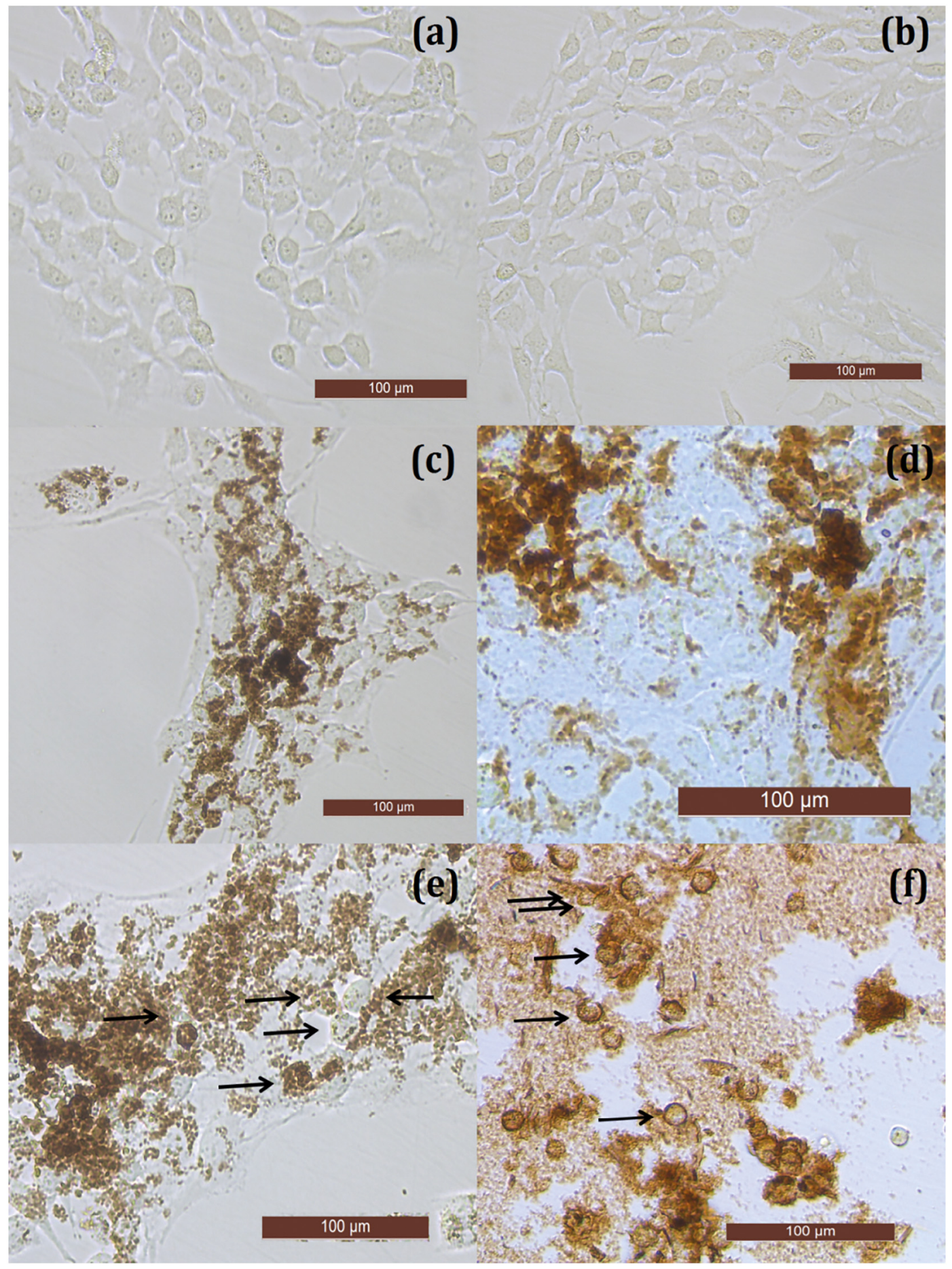

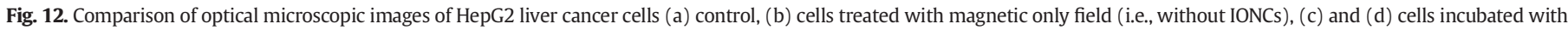

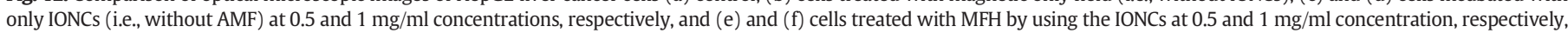
where the black arrows indicate the rounded morphology of cancer cells after MFH treatment. 
periods is determined via MTT assay, and the corresponding cell viability (\%) graph is given in Supplementary data - refer Fig. S2. It can be observed that the IONCs have not induced any cytotoxicity (at all concentrations) towards HepG 2 cells at $24 \mathrm{~h} / 48 \mathrm{~h}$ incubation periods within the concentration range. Thus, the IONCs are found to be highly cytocompatible with the HepG2 liver cancer cells.

Furthermore, the cell uptake of the IONCs (i.e., S6/NCAFF-3 at $15 \mu \mathrm{g}_{\mathrm{Fe}}$ - in terms of iron (Fe) ions) is evaluated via Prussian blue staining method, and the corresponding microscopic images are given in Supplementary data - refer Fig. S3 (a-d). No blue staining is observed for the control cells (i.e., without IONCs) after $24 \mathrm{~h}$ and $48 \mathrm{~h}$ incubation as per Fig. S3 (a) \& (b) respectively. Nevertheless, the cells that are incubated with IONCs for $24 \mathrm{~h}$ and $48 \mathrm{~h}$ have displayed the Prussian blue staining - as confirmed from their respective microscopic images in Fig. S3 (c) \& (d), respectively. Hence, these microscopic images confirm the effective uptake of IONCs by HepG2 cells.

\subsection{In vitro MFH therapeutic studies}

In vitro MFH therapeutic investigations for the selected IONCs (i.e., S6/NCAFF-3 which has displayed enhanced heating effects near to the BPSL) is determined in HepG2 (liver) cancer cells at two concentrations - i.e., $\phi_{1}=0.5 \mathrm{mg} / \mathrm{ml}$ and $\phi_{2}=1 \mathrm{mg} / \mathrm{ml}$. Fig. 11 depicts the viability (i.e., the proliferation capacity) plots of the HepG2 cells with/ without MFH therapy, where the viability of the control cells (without $\mathrm{AMF} / \mathrm{IONCs} / \mathrm{MFH}$ ) is fixed as $100 \%$. The HepG2 cells, which are exposed to only AMF (without IONCs), and only IONCs (without AMF), have shown $80-92 \%$ viabilities in comparison to the control. However, the HepG2 cells, treated with the MFH therapy (by using AMF/IONCs at $\phi_{1}$ and $\phi_{2}$ concentrations) at $42{ }^{\circ} \mathrm{C}$ for $1 \mathrm{~h}$, have respectively shown only $\sim 28 \%$ and $\sim 11 \%$ viabilities, as compared to the controls. Thus, the assynthesized IONCs (i) are highly biocompatible at the applied concentrations (without any AMF), and (ii) have shown concentrationdependent high MFH therapeutic efficacies in HepG2 cancer cells by reducing their proliferation capacity.

Moreover, morphological changes in HepG2 cancer cells (with/without MFH therapy) are investigated through the optical microscopy, and the corresponding photographic images are given in Fig. 12 (a-e). It can be seen that no morphological changes are observed for (i) the control HepG2 cells (refer Fig. 12 (a)); (ii) the cells that are exposed to only AMF (refer Fig. 12 (b)); and (iii) the cells that are incubated with only IONCs at concentrations of $\phi_{1}$ and $\phi_{2}$ (refer Fig. 12 (c) and (d), respectively). However, the HepG2 cells have shown altered (well-rounded off) morphologies (marked in black arrows) when treated with the MFH therapy using the IONCs at concentrations of $\phi_{1}$ and $\phi_{2}$ (Fig. 12 (e) and (f), respectively).

Thus, the as-synthesized IONCs based NCAFF-3 (i.e. S6 sample based AFFs) revealed better cytocompatibility, high cellular-uptake, and significant MFH therapeutic abilities in HepG2 liver cancer cells at their lesser concentrations on exposure to the AMF - near to the assessed BPSL.

\section{Conclusions}

In summary, highly water-soluble flower-shaped IONCs (S1-S3, and S4-S6) are successfully synthesized via facile one-pot thermolysis in presence of LSS mixture of TEA and DEG/TTEG at 9:1, 8:2 and 7:3 (v/v) TEA: DEG and TEA:TTEG ratios, respectively. The as prepared $\sim 24-29 \mathrm{~nm}$ IONCs are found to be magnetite $\left(\mathrm{Fe}_{3} \mathrm{O}_{4}\right)$ in phase and functionalized with the TEA-DEG/TEA-TTEG surface coatings. Moreover, the IONCs are found to be superparamagnetic in nature with Ms. value of $\sim 68-78 \mathrm{emu} / \mathrm{g}$, hydrodynamic sizes of $95-192 \mathrm{~nm}$ and $\zeta$ potential values of +46 to $+65 \mathrm{mV}$. The IONCs prepared using 8:2 TEA:DEG $(\mathrm{v} / \mathrm{v})$ ratio, and 8:2 \& 7:3 TEA:TTEG (v/v) ratios (i.e. S2, S5 and S6 samples) have displayed comparatively higher magnetization values (above $70 \mathrm{emu} / \mathrm{g}$ ) and better water dispersibility (above $+50 \mathrm{mV}$ ) as compared to the $\mathrm{S} 1$ /
S3/S4 samples. Hence, these IONCs based aqueous ferrofluids (NCAFF-1, NCAFF-2, and NCAFF-3, respectively) are further selected to investigate their calorimetric MFH heating effects at $0.5-8 \mathrm{mg} / \mathrm{ml}$ concentration by applying the AMF (with $\mathrm{H}^{*}$ f value of $8.2 \mathrm{GA} \mathrm{m}^{-1} \mathrm{~s}^{-1}$ ). The NCAFF-3 has displayed faster temperature rise $\left(42^{\circ} \mathrm{C}\right.$ within $0.7-9.7 \mathrm{~min}$ ) as compared to the NCAFF-1 and NCAFF-2. Moreover, the NCAFF-3 (with $0.5 \mathrm{mg} / \mathrm{ml}$ concentration) has exhibited enhanced power dissipation/heating efficacies with SAR values of $142.4-909.4 \mathrm{~W} / \mathrm{g}_{\mathrm{Fe}}$ and ILP values 4.2-14.7 $\mathrm{nHm}^{2} / \mathrm{kg}$ on exposure to the AMFs (with $\mathrm{H}^{*} \mathrm{f}$ values = 2.4-9.9 GA m ${ }^{-1} \mathrm{~s}^{-1}$ ), respectively. Nevertheless, the NCAFF-3 has revealed highest ILP value of $14.7 \mathrm{nHm}^{2} / \mathrm{kg}$ on exposure to the AMF (i.e. $4.4 \mathrm{GA} \mathrm{m}^{-1} \mathrm{~s}^{-1}$ - very close to the BPSL), which is greater than those reported values of magnetic nanoclusters. Furthermore, the NCAFF-3 has demonstrated improved cytocompatibility, cell-uptake, and substantial MFH therapeutic efficacies in HepG2 liver cancer cells. Thus, the asprepared IONCs based AFFs (NCAFF-3) have great potential to be used as effective heat-inducing agents for MFH applications in cancer therapeutics.

\section{Acknowledgments}

The authors greatly acknowledge the significant funding supports from (i) Shiv Nadar University, Uttar Pradesh, India, and from (ii) Nano Mission Council, Department of Science and Technology, New Delhi, India (Grant No. SR/NM/NS-1141/2015 (G)).

\section{Appendix A. Supplementary data}

Supplementary data to this article can be found online at https://doi. org/10.1016/j.molliq.2018.11.108.

\section{References}

[1] G. Kandasamy, D. Maity, Recent advances in superparamagnetic iron oxide nanoparticles (SPIONs) for in vitro and in vivo cancer nanotheranostics, Int. J. Pharm. 496 (2015) 191-218, https://doi.org/10.1016/j.ijpharm.2015.10.058.

[2] K.C. Barick, S. Singh, D. Bahadur, M.A. Lawande, D.P. Patkar, P.A. Hassan, Carboxyl decorated Fe3O4 nanoparticles for MRI diagnosis and localized hyperthermia, J. Colloid Interface Sci. 418 (2014) 120-125, https://doi.org/10.1016/j.jcis.2013.11.076.

[3] R. Stone, T. Willi, Y. Rosen, O.T. Mefford, F. Alexis, Targeted magnetic hyperthermia, Ther. Deliv. 2 (2011) 815-838, https://doi.org/10.4155/tde.11.48.

[4] L. Maureen, S. Awalpreet, P. Kaur, M.L. Aliru, A.S. Chadha, A. Asea, et al., Hyperthermia using nanoparticles - promises and pitfalls, Int. J. Hyperth. 00 (2016) 1-13, https://doi.org/10.3109/02656736.2015.1120889.

[5] B. Kozissnik, A.C. Bohorquez, J. Dobson, C. Rinaldi, Magnetic fluid hyperthermia: advances, challenges, and opportunity, Int. J. Hyperth. 29 (2013) 706-714, https://doi. org/10.3109/02656736.2013.837200.

[6] S.P. Pawar, S. Biswas, G.P. Kar, S. Bose, High frequency millimetre wave absorbers derived from polymeric nanocomposites, Polymer 84 (2016) 398-419, https://doi. org/10.1016/j.polymer.2016.01.010.

[7] J. Mosayebi, M. Kiyasatfar, S. Laurent, Synthesis, functionalization, and design of magnetic nanoparticles for theranostic applications, Adv. Healthc. Mater. 6 (2017), 1700306. https://doi.org/10.1002/adhm.201700306.

[8] M.L. Mojica Pisciotti, E. Lima, M. Vasquez Mansilla, V.E. Tognoli, H.E. Troiani, A.A. Pasa, et al., In vitro and in vivo experiments with iron oxide nanoparticles functionalized with DEXTRAN or polyethylene glycol for medical applications: magnetic targeting, J. Biomed. Mater. Res. B Appl. Biomater. 102 (2014) 860-868, https:// doi.org/10.1002/jbm.b.33068.

[9] J. Gautier, E. Allard-Vannier, E. Munnier, M. Soucé, I. Chourpa, Recent advances in theranostic nanocarriers of doxorubicin based on iron oxide and gold nanoparticles, J. Control. Release 169 (2013) 48-61, https://doi.org/10.1016/j.jconrel.2013.03.018.

[10] V.F. Cardoso, A. Francesko, C. Ribeiro, M. Bañobre-López, P. Martins, S. LancerosMendez, Advances in magnetic nanoparticles for biomedical applications, Adv. Healthc. Mater. 7 (2018), 1700845. https://doi.org/10.1002/adhm.201700845.

[11] G. Kandasamy, A. Sudame, D. Maity, ATA and TA coated superparamagnetic iron oxide nanoparticles: promising candidates for magnetic hyperthermia therapy, Adv. Mater. Lett. 8 (2017) 873-877, https://doi.org/10.5185/amlett.2017.1730.

[12] M. Salloum, R.H. Ma, D. Weeks, L. Zhu, Controlling nanoparticle delivery in magnetic nanoparticle hyperthermia for cancer treatment: experimental study in agarose gel, Int. J. Hyperth. 24 (2008) 337-345, https://doi.org/10.1080/02656730801907937.

[13] D. Maity, G. Kandasamy, A. Sudame, Superparamagnetic iron oxide nanoparticles (SPIONs) based magnetic hyperthermia: a promising therapy in cancer treatment, in: Leon V. Berhardt (Ed.), Adv. Med. Biol. 117th ed.Nova Science Publishers 2017, pp. 99-160. 
[14] Z. Hedayatnasab, F. Abnisa, W.M.A.W. Daud, Review on magnetic nanoparticles for magnetic nanofluid hyperthermia application, Mater. Des. 123 (2017) 174-196, https://doi.org/10.1016/j.matdes.2017.03.036.

[15] R. Namgung, K. Singha, M.K. Yu, S. Jon, Y.S. Kim, Y. Ahn, et al., Hybrid superparamagnetic iron oxide nanoparticle-branched polyethylenimine magnetoplexes for gene transfection of vascular endothelial cells, Biomaterials 31 (2010) 4204-4213, https://doi.org/10.1016/j.biomaterials.2010.01.123.

[16] S.-J. Huang, J.-H. Ke, G.-J. Chen, L.-F. Wang, One-pot synthesis of PDMAEMA-bound iron oxide nanoparticles for magnetofection, J. Mater. Chem. B 1 (2013) 5916, https://doi.org/10.1039/c3tb21149e.

[17] S. Prijic, L. Prosen, M. Cemazar, J. Scancar, R. Romih, J. Lavrencak, et al., Surface modified magnetic nanoparticles for immuno-gene therapy of murine mammary adenocarcinoma, Biomaterials 33 (2012) 4379-4391, https://doi.org/10.1016/j. biomaterials.2012.02.061.

[18] Y.C. Park, J.B. Smith, T. Pham, R.D. Whitaker, C. Sucato, J. Hamilton, et al., Effect of PEG molecular weight on stability, T2 contrast, cytotoxicity, and cellular uptake of superparamagnetic iron oxide nanoparticles (SPIONs), Colloids Surf. B: Biointerfaces 119 (2014) 106-114, https://doi.org/10.1016/j.colsurfb.2014.04.027.

[19] S. Sharifi, H. Seyednejad, S. Laurent, F. Atyabi, A.A. Saei, M. Mahmoudi, Superparamagnetic iron oxide nanoparticles for in vivo molecular and cellular imaging, Contrast Media Mol. Imaging 10 (2015) 329-355, https://doi.org/10.1002/ cmmi.1638.

[20] L. Li, W. Jiang, K. Luo, H. Song, F. Lan, Y. Wu, et al., Superparamagnetic iron oxide nanoparticles as MRI contrast agents for non-invasive stem cell labeling and tracking, Theranostics 3 (2013) 595-615.

[21] C. Blanco-Andujar, A. Walter, G. Cotin, C. Bordeianu, D. Mertz, D. Felder-Flesch, et al. Design of iron oxide-based nanoparticles for MRI and magnetic hyperthermia, Nanomedicine 11 (2016) 1889-1910, https://doi.org/10.2217/nnm-2016-5001.

[22] W. Wu, Z. Wu, T. Yu, C. Jiang, W.-S. Kim, Recent progress on magnetic iron oxide nanoparticles: synthesis, surface functional strategies and biomedical applications, Sci. Technol. Adv. Mater. 16 (2015), 023501. https://doi.org/10.1088/1468-6996/ $16 / 2 / 023501$.

[23] H. Ai, C. Flask, B. Weinberg, X.-T. Shuai, M.D. Pagel, D. Farrell, et al., Supporting info magnetite-loaded polymeric micelles as ultrasensitive magnetic-resonance probes, Adv. Mater. 17 (2005) 1949-1952, https://doi.org/10.1002/adma.200401904.

[24] D.F. Coral, P. Mendoza Zélis, M. Marciello, M.D.P. Morales, A. Craievich, F.H. Sánchez, et al., Effect of nanoclustering and dipolar interactions in heat generation for magnetic hyperthermia, Langmuir 32 (2016) 1201-1213, https://doi.org/10.1021/acs. langmuir.5b03559.

[25] D. Caruntu, G. Caruntu, Y. Chen, C.J. O'Connor, G. Goloverda, V.L. Kolesnichenko, Synthesis of variable-sized nanocrystals of Fe3O4 with high surface reactivity, Chem. Mater. 16 (2004) 5527-5534, https://doi.org/10.1021/cm0487977.

[26] P. Hugouneng, M. Levy, D. Alloyeau, L. Lartigue, E. Dubois, V. Cabuil, et al., Iron oxide monocrystalline nanoflowers for highly efficient magnetic hyperthermia, J. Phys. Chem. C 116 (2012) 15702-15712, https://doi.org/10.1021/jp3025478.

[27] L.L. Ma, M.D. Feldman, J.M. Tam, A.S. Paranjape, K.K. Cheruku, T.A. Larson, et al., Small multifunctional nanoclusters (nanoroses) for targeted cellular imaging and therapy, ACS Nano 3 (2009) 2686-2696, https://doi.org/10.1021/nn900440e.

[28] C. Kotsmar, K.Y. Yoon, H. Yu, S.Y. Ryoo, J. Barth, S. Shao, et al., Stable citrate-coated iron oxide superparamagnetic nanoclusters at high salinity, Ind. Eng. Chem. Res. 49 (2010) 12435-12443, https://doi.org/10.1021/ie1010965.

[29] L. Lartigue, P. Hugounenq, D. Alloyeau, S.P. Clarke, M. Lévy, J.C. Bacri, et al., Cooperative organization in iron oxide multi-core nanoparticles potentiates their efficiency as heating mediators and MRI contrast agents, ACS Nano 6 (2012) 10935-10949, https://doi.org/10.1021/nn304477s.

[30] G. Hemery, A.C. Keyes, E. Garaio, I. Rodrigo, J.A. Garcia, F. Plazaola, et al., Tuning sizes, morphologies, and magnetic properties of monocore versus multicore iron oxide nanoparticles through the controlled addition of water in the polyol synthesis, Inorg. Chem. 56 (2017) 8232-8243, https://doi.org/10.1021/acs.inorgchem. 7b00956.

[31] H. Gavilán, A. Kowalski, D. Heinke, A. Sugunan, J. Sommertune, M. Varón, et al., Colloidal flower-shaped iron oxide nanoparticles: synthesis strategies and coatings, Part. Part. Syst. Charact. 34 (2017), 1700094. https://doi.org/10.1002/ppsc. 201700094.
[32] A. Sathya, S. Kalyani, S. Ranoo, J. Philip, One-step microwave-assisted synthesis of water-dispersible Fe 304 magnetic nanoclusters for hyperthermia applications, J. Magn. Magn. Mater. 439 (2017) 107-113, https://doi.org/10.1016/j.jmmm.2017. 05.018.

[33] D. Maity, P. Chandrasekharan, P. Pradhan, K.-H. Chuang, J.-M. Xue, S.-S. Feng, et al., Novel synthesis of superparamagnetic magnetite nanoclusters for biomedical applications, J. Mater. Chem. 21 (2011), 14717. https://doi.org/10.1039/c1jm11982f.

[34] R. Hergt, S. Dutz, Magnetic particle hyperthermia-biophysical limitations of a visionary tumour therapy, J. Magn. Magn. Mater. 311 (2007) 187-192, https://doi.org/10. 1016/j.jmmm.2006.10.1156.

[35] M. Das, D. Mishra, P. Dhak, S. Gupta, T.K. Maiti, A. Basak, et al., Biofunctionalized, phosphonate-grafted, ultrasmall iron oxide nanoparticles for combined targeted cancer therapy and multimodal imaging, Small 5 (2009) 2883-2893, https://doi. org/10.1002/smll.200901219.

[36] G. Kandasamy, A. Sudame, P. Bhati, A. Chakrabarty, D. Maity, Systematic investigations on heating effects of carboxyl-amine functionalized superparamagnetic iron oxide nanoparticles (SPIONs) based ferrofluids for in vitro cancer hyperthermia therapy, J. Mol. Liq. 256 (2018) 224-237, https://doi.org/10.1016/j.molliq.2018.02. 029.

[37] G. Kandasamy, A. Sudame, T. Luthra, K. Saini, D. Maity, Functionalized hydrophilic superparamagnetic iron oxide nanoparticles for magnetic fluid hyperthermia application in liver cancer treatment, ACS Omega 3 (2018) 3991-4005, https://doi.org/ 10.1021/acsomega.8b00207.

[38] M. Kallumadil, M. Tada, T. Nakagawa, M. Abe, P. Southern, Q.A. Pankhurst, Suitability of commercial colloids for magnetic hyperthermia, J. Magn. Magn. Mater. 321 (2009) 1509-1513, https://doi.org/10.1016/j.jmmm.2009.02.075.

[39] D. Maity, P. Chandrasekharan, C.-T. Yang, K.-H. Chuang, B. Shuter, J.-M. Xue, et al. Facile synthesis of water-stable magnetite nanoparticles for clinical MRI and magnetic hyperthermia applications, Nanomedicine 5 (2010) 1571-1584, https://doi. org/10.2217/nnm.10.77.

[40] D. Maity, P. Pradhan, P. Chandrasekharan, S.N. Kale, B. Shuter, D. Bahadur, et al., Synthesis of hydrophilic superparamagnetic magnetite nanoparticles via thermal decomposition of $\mathrm{Fe}$ (acac)3 in 80 Vol\% TREG + 20 Vol\% TREM, J. Nanosci. Nanotechnol. 11 (2011) 2730-2734, https://doi.org/10.1166/jnn.2011.2693.

[41] D. Maity, S.N. Kale, R. Kaul-Ghanekar, J.-M. Xue, J. Ding, Studies of magnetite nanoparticles synthesized by thermal decomposition of iron (III) acetylacetonate in tri (ethylene glycol), J. Magn. Magn. Mater. 321 (2009) 3093-3098, https://doi.org/ 10.1016/j.jmmm.2009.05.020.

[42] S. Ilyas, M. Ilyas, R.A.L. Van Der Hoorn, S. Mathur, Selective conjugation of proteins by mining active proteomes through click-functionalized magnetic nanoparticles, ACS Nano 7 (2013) 9655-9663, https://doi.org/10.1021/nn402382g.

[43] G. Kandasamy, S. Soni, K. Sushmita, N.S. Veerapu, S. Bose, D. Maity, One-step synthesis of hydrophilic functionalized and cytocompatible superparamagnetic iron oxide nanoparticles (SPIONs) based aqueous ferrofluids for biomedical applications, J. Mol. Liq. (2018)https://doi.org/10.1016/j.molliq.2018.10.161.

44] G. Kandasamy, A. Sudame, P. Bhati, A. Chakrabarty, S.N. Kale, D. Maity, Systematic magnetic fluid hyperthermia studies of carboxyl functionalized hydrophilic superparamagnetic iron oxide nanoparticles based ferrofluids, J. Colloid Interface Sci. 514 (2018) 534-543, https://doi.org/10.1016/j.jcis.2017.12.064.

[45] D. Cabrera, J. Camarero, D. Ortega, F.J. Teran, Influence of the aggregation, concentration, and viscosity on the nanomagnetism of iron oxide nanoparticle colloids for magnetic hyperthermia, J. Nanopart. Res. 17 (2015)https://doi.org/10.1007/ s11051-015-2921-9.

[46] P. I P Soares, F. Lochte, C. Echeverria, L. C J Pereira, J. T Coutinho, I. M M Ferreira, et al., Thermal and magnetic properties of iron oxide colloids: influence of surfactants, Nanotechnology 26 (2015), 425704. https://doi.org/10.1088/0957-4484/26/42/ 425704.

[47] I. Conde-Leboran, D. Baldomir, C. Martinez-Boubeta, O. Chubykalo-Fesenko, M. del Puerto Morales, G. Salas, et al., A single picture explains diversity of hyperthermia response of magnetic nanoparticles, J. Phys. Chem. C 119 (2015) 15698-15706, https://doi.org/10.1021/acs.jpcc.5b02555. 